\title{
Regulatory Network of MiRNAs, IncRNAs, Transcription Factors and Target Genes Associated With Immune Response in Bovine Mastitis
}

\author{
Ashley R. Tucker
}

Rochester Institute of Technology

Nicole A. Salazar

Rochester Institute of Technology

Adeola O. Ayoola

Chinese Academy of Sciences

Erdoğan Memili

Mississippi State University

Bolaji N. Thomas

Rochester Institute of Technology

Olanrewaju B. Morenikeji ( $\boldsymbol{\nabla}$ omorenik@hamilton.edu )

Hamilton College

\section{Research Article}

Keywords: IncRNA, miRNA, transcription factor, prediction, markers, regulation, bovine mastitis

Posted Date: April 26th, 2021

DOl: https://doi.org/10.21203/rs.3.rs-434766/v1

License: (1) This work is licensed under a Creative Commons Attribution 4.0 International License.

Read Full License 


\section{Abstract}

Background: Bovine mastitis is a mammary gland infectious disease caused by a variety of pathogens with a devasting economic impact worldwide. Pre- and post-transcriptional modifications, including transcription factors (TFs), altering gene expression are emerging foci of disease studies, with minimal studies revealing the importance of non-coding transcripts, like long non-coding RNAs (IncRNAs) and microRNAs (miRNAs). We hypothesize TFs, IncRNAs and miRNAs can modulate the immune response in bovine mastitis and can potentially serve as disease biomarkers and/or drug targets.

Methods: With computational analyses, we aimed to identify candidate bovine mastitis genes and construct the networks of miRNA, IncRNA and TFs regulating the gene's mRNA, affecting disease pathogenesis. Experimentally validated genes associated with bovine mastitis were obtained through an extensive search for significantly mentioned genes, utilizing several databases. Prediction of miRNA and IncRNA binding bovine mastitis candidate genes were performed through several algorithms and software that relied on base pair complementation, evolutionary conservation, and thermodynamic stability of binding regions. Combined interactome network of IncRNAs, miRNAs, TFs and immune gene targets were constructed.

Results: Sixteen of 923 genes were found to be highly significant in bovine mastitis disease pathway including, CD4, IL-10, IFNy, IL-4, TLR4, TNFa, and CD14. Remarkably, we found six miRNAs, two being btamiR-223 and bta-miR-24-3p, to bind to several targets. Eight out of 22 IncRNA, such as NONBTAT027932.1 and XR_003029725.1, were identified as regulatory elements that target the genes based on the normalized binding free energies ranging from -0.1774 to -2.875 . Similarly identified were 17 TFs, including JUN and CREB. Our functional and pathway analyses revealed several pathways like lipopolysaccharide-mediated signaling pathway, regulation of chemokine (C-X-C motif) ligand 2 production and regulation of IL-23 production among others.

Conclusions: The overarching interactome in this study is the first of its kind regarding bovine mastitis, deserving further in vitro/in vivo explication for specific molecular regulatory mechanisms during bovine mastitis immune response, which could lay the foundation for development of disease markers and therapeutic intervention.

\section{Background}

Bovine mastitis, caused by a variety of organisms, including Staphylococci, Streptococci, and Enterobacteria, is a mammary gland infection posing a great threat to the dairy industry, and is the costliest disease affecting cattle due to its impact on the quality and quantity of milk production $[1,2]$. The immune response to pathogens in the mammary glands is highly complex, having to first identify the pathogen, recruit the appropriate immune cells, remove the pathogen, and then terminate the inflammatory response [3]. Recent studies have shown that mammary epithelial cells (MEC) initiate this process by changing the expression of various genes, responsible for a wide range of immunological and 
inflammatory responses [4].. The regulatory elements involved in the over- or under-expression of these genes during bovine mastitis are yet to be fully understood and may be a potential area for initiating prevention and control of a global, economically devastating disease in the dairy industry.

Of recent, attention has shifted to regulatory elements, such as microRNAs (miRNAs), long non-coding RNAs (IncRNAs), and transcription factors (TFs), possibly influencing the expression of host immune genes $[5,6]$. MiRNAs are short, non-coding RNA that bind to the $3^{\prime}$ untranslated region (UTR), 5'UTR and coding regions of an mRNA to post-transcriptionally modify genes, repressing their translation into their final protein product $[5,7]$. Likewise, IncRNAs are long non-coding RNA transcripts, harboring a $5^{\prime}$ cap and 3 ' poly (A) tail but no functional open reading frame, and as such cannot encode proteins $[8,9]$. This heterogeneous class of RNAs can modulate gene expression and protein synthesis at the transcriptional, post-transcriptional, translational, and post-translational levels via complementary base pairing [10]. LncRNAs play key roles in regulating several cellular and developmental processes, including genomic imprinting, DNA methylation, splicing and chromatin modification $[11,12]$. With an abundance of binding sites for miRNA and mRNA, IncRNA can act as ceRNA (competing endogenous RNA) and are significant regulatory elements in post-transcriptional gene expression $[13,14]$. For example, IncRNA adipocyte differentiation-associated long noncoding RNA (ADNCR) targets miR-204 significantly regulating Sirtuin 1 (SIRT1) gene expression at the mRNA and protein level, inhibiting adipogenesis in the process [15]. Additionally, Li and colleagues showed that IncRNA H19 targets miRNAs let-7b and miR-200b, competes endogenously with transcription factor Sp1 (SP1), thereby regulating the expression of TGF- $\beta$-receptor 2 (TGFBR2) gene in all cancers [9]. On the other hand, TFs are proteins capable of altering or activating gene-expression level $[16,17]$.

Here, we propose a need to understand the crosstalk between miRNA, IncRNA and TFs, and the role they play in regulating genes associated with bovine mastitis, including the possibility of translation to drug treatment or disease prevention therapies. To do this, we identified candidate miRNAs, IncRNAs and TFs, and their potential role in bovine mastitis via in silico analyses. Current algorithms, relying on base pair complementation, evolutionary conservation, and thermodynamic stability of binding regions, have been shown to be useful in predicting miRNA, IncRNA and TF binding sites on target genes $[18,19]$. Multiple miRNA databases such as miRWalk [20], miRNet [21], and TargetScan [22] compute potential miRNAmRNA interactions, while the role of individual miRNA can be inferred through functional analysis with Gene Ontology (GO) [23]. Similarly, IncRNA prediction binding software including NONCODE [24], IncRNA2Target [25], and IncTar [19] have been useful in guiding bench experiments thereby saving time and resources.

Knowing the interconnectivity of key regulatory elements involved in bovine mastitis is potentially useful in disease detection, especially in subclinical cases. If a regulatory element plays a key role in disease pathogenesis or in the immune response, this may be an ideal drug target for treatment. Therefore, we aim to identify significant miRNA, IncRNA, and TFs for previously identified candidate genes, and determine which of the regulatory elements/factors could be further validated as potential drug target for bovine mastitis. 


\section{Results}

\section{Dataset of candidate genes associated with immune response to bovine mastitis}

Our initial search on PubMed using the keywords "bovine," "mastitis," "immunity," and "genes" generated 276 articles. Following filtering, a total of 109 articles were selected and added to the pipeline for candidate genes identification. These articles, including experimental, meta-analysis, and reviews mentioned 919 individual genes associated with host immune response to bovine mastitis. Of importance to our analysis are genes with multiple mentions, including CXCL8 and IL-6 referenced in 41 and 29 articles, respectively (Fig 1b). Comparing the 919 genes found during our search with the 20 genes generated from Genomatix, yielded 16 genes that were common to both search methods (Supplementary Fig 1). These genes are MYD88, CD4, IL-10, IFNy, IL-4, ICAM1, CXCL8, TLR4, TNFa, IL-18, TLR2, CD86, CCL2, IL-6, CSF2, and CD14. The interactions between these candidate genes reveal TLR4 and TLR2 are considerably more linked to other genes (Fig 2), while CD4 on the other hand had the least interaction.

\section{miRNAs bind to the candidate genes in bovine mastitis}

Our analyses explored the complementarily binding of miRNAs to the $3^{\prime} U T R, C D S$, and $5^{\prime} U T R$ regions of the candidate genes. We report a total of 768 miRNAs binding either the $3^{\prime}$ UTR, CDS, or 5' UTR of the 16 target genes (Supplementary Table 2). With BEG, five miRNAs were uncovered to bind all three regions within the same gene: bta-miR-2338 and bta-miR-2433 to CD14, bta-miR-2373-3p to ICAM1, bta-miR2328-3p and bta-miR-2356 to TLR4 (Fig. 3). In addition, a substantial number of miRNAs bound to two or more regions within the same gene (Fig. 3), Displaying all the miRNA predicted to bind to three or more target genes is Fig. 4, which also depicts whether the miRNA binds one (green), two (blue), or three (red) of the possible regions ( $\mathrm{S}^{\prime} \mathrm{UTR}, 5^{\prime} \mathrm{UTR}$, and CDS). The complete list of miRNAs binding three or more target genes is depicted in Supplementary Table 3. Likewise, we found six miRNAs; bta-miR-24-3p, btamiR-149-5p, bta-miR-223, bta-miR-185, bta-miR-874, and bta-miR-328, commonly predicted by the three software as shown (Supplementary Fig 2; Supplementary Table 2).

\section{IncRNAs interact with mRNA target inferring their functionalities}

NONCODE database search revealed 22 bovine IncRNAs that matched our prediction criteria. Genomic location and strand sense for each IncRNAs are shown in Supplementary Table 4. From the analysis, we identified 20 IncRNAs that bind to our target mRNAs with a ndG $<-0.05$ (Fig 5 and Supplementary Table 4), with 8 of them targeting more than 13 of disease associated genes. Of the 8 IncRNA, six (NONBTAT001181.2, XR_003029725.1, NONBTAT010129.2, XR_003030515.1, XR_003033296.1, NONBTAT027932.1) targeted all of the16 genes, while NONBTAT027932.1, XR_003033296.1, and XR_003029725.1 could bind at least one target gene with an average ndG greater than -0.08 . NONBTAT001181.2-IL-18 and XR_003029725.1 showed a high affinity for IL-18 with thresholds less than -0.1. Additionally, NONBTAT027932.1 could bind MYD88, CD4, ICAM1, CD14, TLR2, and TNFa with binding free energy less than -0.1 (Supplementary Table 4). Eight IncRNAs that bind 13 or more candidate 
genes with lower ndGs were selected for network and conservational analysis (Table 3). Most of the identified IncRNAs are not yet annotated, therefore, we inferred their gene ontology and pathways based on their potential mRNA targets/genes. Identified ontologies and associated pathways are shown in Table 4 and Figure $6 a$ and $6 \mathrm{~b}$.

\section{Biological, molecular and cellular function of target genes and pathway analysis}

The pathway analysis of 16 target genes identified 25 biological processes (Fig 6a). Myeloid leukocyte activation with a p-value of 4.92E-13 vascular endothelial growth factor (GF) production, regulation of chemokine (C-X-C motif) ligand 2 production and lipopolysaccharide (LPS)-mediated signaling pathway (p-value; 2.58E-13) (Table 4). Of importance are the three significant biological processes concomitantly identified from the three databases including LPS-mediated signaling pathway, regulation of IL-23 production, and positive regulation of chemokine production. DAVID analysis identified eight biological processes, three molecular functions and one cellular component, while 11 disease pathways were identified including malaria and rheumatoid arthritis that featured most candidate genes during bovine mastitis with p-values of 9.20E-19 and 4.60E-16, respectively (Fig 6b; Supplementary Table 5).

\section{Catalog of transcription factors, biological processes and molecular function}

Seventeen TFs were identified as significant by at least two software (Table 5; Supplementary Table 6). All 17 TFs appear to have the potential to regulate the transcription of the 16 genes including CD4, MYD88, ICAM1, TLR4, TLR2, IL-18, and CD86. The genomic location and other details of the 17 TFs are presented in Table 5. In addition, functional analysis identified 3 biological processes, 2 molecular functions, and 1 cellular component involving two to three TFs, with a p-value less than 0.0005 (Table 6).

\section{Sequence conservation of bovine miRNA and IncRNAs in other species}

Sequence analysis was performed to assess the evolutionary conservation of bovine IncRNAs and miRNAs across various species (Supplementary Table 1). We examined the significant miRNA (6) and IncRNA (8) identified previously with their homologous sequence from 14 other species. Our analysis of the six miRNAs reveal bta-miR-223 to be highly conserved in all 15 species, without a single deviant polymorphism (Supplementary Fig 3). The evolutionary closeness of the cow and wild yak is also seen in bta-miR-149-5p, bta-miR-328, and bta-miR-185, but are distantly related in bta-miR-24-3p and bta-miR-874 (Supplementary Fig. 4a-c). The phylogenetic analysis of bta-miR-223 defines cow having the closest identity with wild yak and the remaining ruminants (goat and sheep) as orthologs (Supplementary Fig 4b). The alignment of bta-miR-874 showed high conservation between cow, mouse, and megabat, with phylogenetic analysis having these three sharing a common node, while no other tree had these three species this close in proximity.

The length of IncRNA allow for greater variation within the gene throughout evolution. The evolutionary alignment analysis revealed that each IncRNA was not completely conserved in the 15 species; however, the majority have similar base pair sequences in conserved regions. Out of the 8 IncRNA, 7 have bovine 
IncRNA to be most closely related to wild yak, followed by other ruminants (Supplementary Fig. 5a-d). The tree of NONBTAT027932.1 show wild yak to be relatively distant from cow, sheep, and goat compared to the species relation in the other IncRNA analysis. Five out of eight IncRNA have human, gorilla, and chimpanzee clustered with the same origin.

\section{Dysregulation of IncRNA-miRNA interaction on immune response in bovine mastitis}

Our analysis showed several miRNA potential binding sites on IncRNA, based on the complementary base pairing and normalized binding free energies (ndG) values. Of interest, we found 8 out of 22 IncRNAs possessing binding sites for the entire length of these miRNAs, with the exception of 4 out of the 48 pairings (Fig 7). The ndG values range from -0.1774 to -2.875. IncRNA XR_003033296.1 and bta-miR-223 had the greatest ndG while IncRNA XR_234647.4 and bta-miR-328 had the lowest ndG. The lower the ndG, the greater the possibility that the two RNA will bind. The vast majority of miRNA bind their entire length to the IncRNA except four, the shortest binding length is 10 (out of 22 base pairs) between bta-miR-223 and XR_234647.4. Additional results on IncRNA-miRNA binding are presented in Supplementary Table 7.

\section{Combined network and molecular interactome of IncRNAs, miRNAs, TFs and immune genes}

Figures 8 through 11 show molecular interactions between miRNAs, IncRNAs, TFs, target genes and pathways. Figure 8 in particular show the connections between the bovine mastitis target genes, miRNA, and the pathways/biological processes of the genes. CD4 (36) and TLR4 (36) have the most miRNA targeting them, as opposed to IL-4, CSF2, and IL-18 (one, two and two miRNAs respectively). Some miRNAs are seen targeting more than one gene such as bta-miR-2294 (targeting CD4 and CD86) and btamiR-2374 (targeting TLR4 and CD4). Interestingly, we found some miRNAs that bind to multiple genes involved in the same pathway, such as bta-miR-671 targeting TLR4 and IFNy, both of which are involved in macrophage activation; bta-miR-2413 targeting IFNy, IL-10, and TLR4, all of which are involved in the regulation of nitric oxide biosynthetic process.

The functional annotation of each IncRNA was inferred from the target genes using GO Enrichment Analysis and the DAVID KEGG algorithm program. Several of these IncRNAs were involved in multiple ontologies (Figure 9). Specifically, NONBTAT001181.2 could bind to IL-6 to regulate its expression, thereby perturbing functional pathways like vascular endothelial growth factor, regulation of cytokine production, which are involved in inflammatory response, and regulation of tyrosine phosphorylation of STAT protein pathways. LncRNA XR_003030515.1 targets TLR4 and is connected to cellular response to lipoteichoic acid, macrophage activation, NAD+ nucleosidase activity, and regulation of interleukin-23 production. NONBTAT027932.1 IncRNA targets CD14 and is involved in positive regulation of NIK/NF-KB signaling, regulation of interleukin-8 production, regulation of cytokine secretion, LPS-mediated signaling pathway, lipopeptide binding, and LPS receptor complex (Figure 9). Figure 10 shows the interconnections between the 17 TFs, 16 target genes, and the pathways they are involved in. Both CREB1 and JUN have numerous connections directed toward the target genes and pathways. 
The final immunoregulatory integrated network in our analysis contains miRNAs, IncRNAs, TFs, target genes, and biological pathways and their extensive interconnections (Fig 11). We showed an important connectivity between IncRNA, miRNA, bovine mastitis immune genes and that their biological functions have all been mapped on the network. The outer circle contains mostly miRNAs, with the exception of 3 TFs, that bind only to a single target gene. The inner circle consists of miRNAs binding to more than one target gene, IncRNAs, TFs, target genes, and biological pathways. LncRNA are found densely in the top inner circle and can be sporadically located in the outer circle. Our results indicate that the majority of IncRNAs, miRNAs, and TFs interactions overlapped and were involved in several pathways including biological processes, cellular components, and molecular functions.

\section{Discussion}

Bovine mastitis is detrimental to the dairy industry with significant impacts on farms in developing countries [26, 27]. Mastitis can become chronic and highly contagious, and the effective treatment options available are suboptimal, one reason being the cost accompanied with antibiotic residue in the milk [28]. Regulatory factors have been associated with other diseases, including atherosclerosis, identifying a IncRNA that may be an intuitive preventive and therapeutic treatment option [29] but not in bovine mastitis. Novel key IncRNA and TFs were identified in lung adenocarcinoma regulatory networks, offering new drug targets for therapeutic treatments [30]. In another study, miR-99b was found to repress the expression of IGF1R and mTOR, ultimately acting as an onco-suppressor in clear cell renal cell carcinoma [31]. To our knowledge, this is the first report examining all three regulatory elements (miRNA, IncRNA and TFs) in the context of bovine mastitis, with the aim to identify elements influencing expression of candidate genes regulating immune response.

Through our meta-analysis and computational mining, we generated a list of genes playing critical roles in immune response during bovine mastitis. TLR2 and TLR4 were substantially connected to other candidate genes through our network, which is expected given their involvement in pro-inflammatory and innate immune response [32]. Specifically, TLR4 recognizes lipopolysaccharides found in the outer membrane of gram-negative bacteria and TLR2 recognizes lipoteichoic acid found in the cell wall of gram-positive bacteria [33]. Pathogen recognition is imperative to the initiation of the immune response, and without TLR4 and TLR2, identification of bacteria in bovine mammary epithelial cells would be impaired. IL-8, IL-6 and TNFa, the three most common genes in our meta-analysis, are all inflammatory cytokines or chemokines, and have been shown to be upregulated in bovine mammary epithelial cells stimulated with LPS [34].

Of importance, our results identified six miRNAs binding to several target genes with the potential to regulate their expression during bovine mastitis. Interestingly, previous studies have shown bta-miR-24$3 p$, bta-miR-328, bta-miR-223, and bta-miR-185to be associated with bovine immune response. Bta-miR24-3p has been associated with serum antibody response to Mycoplasma bovis in beef cattle [35]. BtamiR-185 had increased expression in milk from a $S$. aureus infected cow compared to a healthy cow. Ma et al. [36] identified bta-miR-185 targeting five genes including MLLT3, DYRK1B and NPR2. A few other 
studies have demonstrated the involvement of bta-miR-223 in bovine mastitis host immune response [37, 32], but also in other immune responses to lung infection, bacterial peritonitis, and cutaneous leishmaniasis [38-41]. The other two miRNA identified in our study, bta-mir-149-5p and bta-miR-874, have been associated with fat levels in beef cattle [42, 43]. Our findings along with previous publications collectively demonstrate the involvement of these miRNAs in immune response and should be strongly considered for further laboratory studies. In addition, our study demonstrated that miRNAs that could bind to all three regions on a single gene had a greater probability of binding the target gene, and ultimately perturb the disease pathways the target genes are involved in.

Furthermore, we identified novel interaction between IncRNA and mRNAs that could mediate host immune response at the post-transcriptional level. IncRNAs are becoming known to be involved in several biogenetic processes that may regulate disease pathogenesis $[44,14]$. We hypothesize that IncRNAs that bind to multiple mRNA target sequences could serve as significant drug targets and have the potential to modify or regulate immune signaling pathways, ameliorating the over- or under-production of cytokines or chemokine during infection. Importantly, IncRNAs could directly bind to the mRNA thereby getting it degraded and prevent translation to the expected protein. Of interest, we also found several IncRNAs with binding sites for miRNAs, for example XR_003033296.1-bta-miR-223 and IncRNA XR_234647.4-bta-miR328 interactions thereby providing a way to prevent the negative regulatory effect of miRNA on the mRNA targets during disease perturbation. Gene ontology analysis reveal several of these miRNAs and IncRNAs to be associated with myeloid leukocyte activation, LPS-mediated signaling pathway, and positive regulation of IL-8 production. These miRNAs and IncRNAs interactions may be an avenue to manipulate of the regulatory elements involved in immune response to bovine mastitis. The knowledge is potentially useful in disease detection/diagnosis, especially in subclinical cases and may be an ideal target for treatment $[15,45]$.

Additionally, our pathway analysis revealed seven genes, IL-4, IFNY, TLR4, CXCL8, IL-18, CSF2 and TNFa, are involved in the morphological and behavioral changes of macrophages, monocytes, granulocytes, and dendritic cells (DCs) and their recruitment into infection sites. Therefore, the miRNA binding to these seven genes transcripts and degrade their mRNA would have a deleterious effect on the immune response needed to eliminate the pathogen. Our study indicated bta-miR-328 and bta-miR-223 bind to three out of the seven genes involved in this pathway. A recent study found the overexpression of btamiR-223 in Mac T cells attenuating the inflammatory response induced by lipoteichoic acid derived from $S$. aureus, by targeting the Cbl proto-oncogeneB (CBLB), positively correlated with the expression of P13K, AKT, and NF-KB p65 [37]. Fang and others concluded that bta-miR-223 is a central post-transcriptional regulator in mammary tissue when infected with $S$. aureus by altering the expression of key innate immune response genes, one being CXCL14 [32]. Other studies have also identified bta-miR-223 as a key miRNA expressed in mammary tissue during bovine mastitis [46]. Given our findings and previous reports, we surmise that these six miRNAs, especially bta-miR-223 would play a significant dysregulatory role on immune response during bovine mastitis and could serve as biomarker or drug target, deserving further in vivo and in vitro investigation to clarify. 
Our study showed seven significant transcription factors including SP1, SF1 and JUN targeting several genes within the biological pathways. The SP1, JUN and CREB are commonly found in almost all the significant biological pathways (molecular function, biological and cellular processes), resulting from their function as activators and repressors. SP1 has been identified as one of the first eukaryotic trans activators to regulate numerous mammalian genes, often in association with other transcription factors, playing major roles, including cell cycle regulation, hormonal activation and apoptosis [47, 48]. Jun directly transcribe the expression of epidermal growth factor receptor thereby positively regulating the proliferation and differentiation of keratinocyte [49].

Nuclear transcription factor- $\mathrm{k}(\mathrm{NF}-\mathrm{kB})$ signaling is a major player in the regulation of innate and adaptive immune responses and is widely studied for the role it plays in mastitis progression and pathogenesis. Many inflammatory genes contain binding sites for NF-KB in their promoter regions, thus active NF-KB regulates expression by directly binding to target genes in the nucleus [4]. Cytokines (IL-6, IL-1 $\beta, T N F a)$ and chemokine (CXCL8) are associated with increased expression in LPS-stimulated mammary glands [8, $50,51]$. These pro-inflammatory cells disrupt the blood-milk barrier causing slowed milk production and painful clinical manifestations in cattle with mastitis. Given the immunological and inflammatory importance, IncRNAs targeting mediators (TLR2, TLR4, MYD88, CD14, ICAM-1, IL-6, IL-1 $\beta$, TNFa, and CXCL8) of the NF-KB signaling pathway may act as biomarkers for disease diagnosis and drug therapeutics by blocking IncRNAs from interacting with the target genes.

A variety of growth factors and inflammatory signals induces CREB and subsequently mediate the transcription of genes that contain a cAMP-responsive element. Interestingly, our study identified that miRNAs could bind and regulate IL-6, IL-10, and TNFa, which possess the cAMP-responsive element [52]. IRF1, through the regulation of autoimmunity, inflammation, viral infections, and innate and adaptive immune responses, is also responsible for the protection of host cells [53].

Conservation analysis revealed all six miRNAs to be almost entirely conserved between the 15 species. The bta-miR-223 was highly conserved in all 15 species, without a single base pair difference. The conservation of these miRNAs throughout evolution indicates their importance and benefits to the host, further validating our results. These findings also suggest a drug targeting one of these miRNAs can be used across multiple species. This also suggests the possibility of drug experimental trials on smaller animals that have a higher rate of reproduction, such as a mouse or rat, following in vivo/ in vitro elucidation.

Network interactome of miRNA, target genes, pathways, and cellular functions give a visualization of the connections between them, allowing for comprehension of the broad picture- regulatory element to target gene to biological pathway. For example, bta-miR-671 is predicted to bind to IFNy and TLR4 in at least two of the three mRNA regions, and both IFNy and TLR4 are involved in the positive regulation of tumor necrosis factor superfamily cytokine production. Therefore, bta-miR-671 may be a strong target gene as it affects a biological pathway through two different genes. One of our identified miRNAs, bta-miR-24-3p binds to CD14 in at least two regions. CD14 is involved in cellular response to lipoteichoic acid, Toll-like 
receptor signaling pathway, positive regulation of tumor necrosis factor superfamily cytokine production, positive regulation of cytokine secretion, positive regulation of NIK/NF-KB signaling, regulation of interleukin-8 production, and LPS-mediated signaling pathway, all of which play major roles in immune response. Bta-miR-149-3p targets both CXCL8 and TLR4, both of which are involved in myeloid leukocyte activity. This interactome ties our findings together and allows for miRNA to be seen as possible therapeutic targets.

\section{Conclusions}

The present study provides computational evidence that miRNA, IncRNA, and TFs could regulate the host immune response to bovine mastitis. These regulatory element interactomes provide an insight into immune gene dysregulation during bovine mastitis. The knowledge, which is useful in disease detection/diagnosis, especially in subclinical cases, may be ideal targets as an antibiotic for treatment. Meta-analysis indicated 16 immune-related genes as key components involved in host immune response to bovine mastitis. We identified 6 miRNA, 8 IncRNA, and 17 TFs that could potentially regulate expression of our candidate genes and were deemed significant to our study. Of importance, we reported miRNA bta-miR-223 to be highly conserved across species and targeting multiple genes. Likewise, 6 IncRNAs including NONBTAT027932.1 and XR_003029725.1 bind to all candidate genes while Sp1, JUN, and CREB transcription factors were involved in a majority ontology processes. The crosstalk between these regulatory elements was particularly important to our study, providing a new direction for disease studies in farm animals. Functional network analyses revealed complex interactions, suggesting that our identified significant elements would be effective drug targets for treatment and prevention through vaccination. To validate these predictions, further work is needed with in vitro and in vivo analyses that examine the expression or regulatory role of miRNA, IncRNA and TFs on host immune response in bovine mastitis.

\section{Methods}

\section{Extraction and verification of significantly regulated genes in bovine mastitis}

The analytical pipeline employed for this study, starting from literature search to interaction networks (Fig. 1a), including some amendments has been described previously [7, 54]. Briefly, to obtain experimentally validated genes associated with bovine mastitis, we carried out an extensive search for significantly mentioned genes, utilizing several databases. First, LitInspector (Genomatix version 3.10, Munich, Germany) was used to scan all literature-curated datasets derived from high and low throughput experiments with a Medical Subject Headings (MeSH) on bovine mastitis, as described [7]. We obtained a MeSH-Term ID of C22.196.5819 and a p-value of 48E-31. Identified gene sets were filtered based on the number of reports from PubMed articles, pathway enrichment and gene ontology (G0) [55]. Second, we carried out a meta-analysis on PubMed (https://www.ncbi.nlm.nih.gov/pubmed/) with combination of keywords including bovine mastitis + gene expression, to catalog genes from published literature in the database. We matched the identified genes from both search methods with Bioinformatics and 
Evolutionary Genomics (BEG) Venn diagram generator

(http://bioinformatics.psb.ugent.be/webtools/Venn/) to identify common genes. The overlapped genes between the two lists were selected as our candidate genes (total of 16 genes) and were included for further analysis (Table 1). We then constructed a protein-protein interaction network of the candidate genes with Search Tool for the Retrieval of Interacting Genes database (STRING-DB; string-db.org) to determine molecular interactions and possible mechanisms for co-expression and interconnectivity, from both text mining and experimentally determined datasets [56].

\section{Prediction of miRNA for bovine mastitis candidate genes}

The locations of the 16 identified genes from our analysis were determined within the Bos taurus reference genome (ARS-UCD1.2) and complete transcript sequences were downloaded from GenBank. The transcript information and accession numbers are listed in Table 1. Furthermore, using Bos taurus as the reference organism, we searched for miRNAs that could bind complementarily against the entire region of each of our candidate genes, including the 5'-UTR, CDS, and 3'-UTR, using the prediction software miRWalk [20]. MiRNA binding to any of the three regions with a maximum p-value of 1 was used for further selection. To evade false positive in our analysis, the generated list of miRNA were cross referenced with two other prediction software, miRNet [21] and TargetScan [22] as described [7]. Using Venn generator, the overlap of predicted miRNA from the three software were selected as significant for further analysis (Table 2).

\section{Identification of IncRNAs associated with immune response during bovine mastitis}

In order to identify putative IncRNAs within cattle genome that may be binding to the transcript sequences thereby regulating expression, we performed a genome-wide search based on the publicly available curated data from four databases: NONCODE [24] a comprehensive knowledge based ncRNA database that specifically focuses on IncRNA; LncTar [19] a IncRNA-RNA prediction software using the minimum binding free energy between RNA sequences; Ensembl (http://useast.ensembl.org/index.html), a vertebrate genome browser supporting analysis software, and LncRNA2Target v2.0 [25], a comprehensive database of IncRNA-target relationships, manually curated from published IncRNAfocused articles. Briefly, we searched each database for IncRNAs using cow as reference. Due to the high number of IncRNAs within the genome, we made some assumptions and applied the most stringent filter criteria using: 1 . The number of exons, believing more exons imply high quality transcripts; we selected only IncRNAs with exon number greater than two. 2. Longer transcript length gives better quality transcripts; transcript length $>200$ bp were selected. 3 . The prediction score; a lower score means a higher quality transcript; prediction score less than -0.2 was used. 4. Finally, we selected only IncRNAs that meet criteria 1-3 and also found in minimum of three out of the four databases. Briefly, complete sequences of each IncRNA were retrieved from NONCODE and each sequence searched on the bovine genome ARSUCD1.2. using the Ensembl BLAT/BLAST genomic sequencing tools. NCBI BLAST was used to identify available accession numbers for each IncRNA (Table 3). Using LncTar, each mRNA gene was used as target to determine if bovine IncRNAs binds to the mRNA target. Based on the normalized free binding 
energy (ndG) value from the nucleotide base pairing, dataset with less than -0.05 were considered significant and used as candidates for further analysis [19].To avoid false positive IncRNAs, we used LncRNA2Target v2.0 as a second IncRNA-mRNA prediction software with human homology for the 16 target genes to determine bovine IncRNA binding sites. We located all identified human IncRNAs counterparts on the bovine genome ARS-UCD1.2. The IncRNAs found in bovine genome ARS-UCD1.2 and the human genome GRCh38 e were significant to our study.

\section{Prediction of significant transcription factors}

Transcription factors and their corresponding binding sites were predicted for the genes using different prediction software; AnimalTFDB [57] and GeneXplain [58], so as to increase result accuracy. AnimalTFDB was employed using the default settings with the p-value cut off at the minimum of e-06. For GeneXplain, both Match and P-Match algorithms were adjusted to use the cut off selection " 1.0 and 1.0 " as matrix similarity cut-off and core similarity cut-off. We included only seventeen TFs that appeared in the results of at least two software for further analysis.

\section{Functional and pathway analysis of candidate genes associated with immune response to bovine mastitis}

Functional enrichment analysis, using geneontology.org, was performed on the 16 candidate genes to determine the molecular functions, biological processes and cellular components the genes are involved in as described [14, 59], with slight changes. Using the fold enrichment of greater than 100 , the false discovery rate (FDR) of $<10^{-5}$, and the p-value of $<10^{-7}$, we catalogue the biological processes and cellular components. The molecular functions were selected based on the following criteria; fold enrichment $>100, F D R<0.001$, and the $p$-value was $<0.01$. To validate these findings, we carried out functional analysis with Database for Annotation, Visualization and Integrated Discovery (DAVID) [60], using the same parameters as stated previously. Results common in both programs were used for further analysis. Significant pathways were generated using KEGG program algorithms with fold enrichment of $>40$, while the $\mathrm{p}$-value and FDR were $<10^{-4}$.

\section{Sequence conservation analysis of significant miRNA and IncRNA}

Using miRBase [61], candidate miRNAs sequences were retrieved and ascertained using the BLAST against cow, dog, cat, pig, human, gorilla, chicken, goat, rat, megabat, horse, mouse, wild yak, sheep, and chimpanzee for conservation analysis (Supplementary Table 1). MEGAX [62] and MultiAlin [63] were used to align miRNA sequences from each species to determine the regions of conservation and construct a phylogenetic tree. The tree was exported as a Newick text-file and uploaded to iTOL [64] for further editing. Furthermore, IncRNA sequences extracted from NONCODE were compared using multiple sequence alignment and phylogenetic analyses to detect evolutionary profile across 15 species using MEGA X. The phylogenetic trees were also imported to iTOL for further editing and visualization. 
We hypothesized that a complementary base pairing or binding of miRNA and IncRNA would be an important mechanism to manipulate the regulatory elements involved in immune response to bovine mastitis. To do this, we predicted the possible miRNA binding sites on the IncRNA sequences and determine their normalized binding free energy (ndG) based on the complementary base pairing, using LncTar [19]. Furthermore, miRNA, IncRNA, their target genes, and the biological processes were connected on a critical network using Cytoscape version 3.7.2, as described previously $[54,65]$.

\section{Combined interactome network of IncRNAs, miRNAs, TFs and immune gene targets}

To provide information on the connectivity as well as to identify the molecular mechanisms for gene regulation between the candidate genes, miRNAs, IncRNAs, and TFs, we created an interactome network with Cytoscape software, version 3.7.2. Network of different nodes were created based on all identified RNAs, TFs and associated pathways, while the network edges determine the relationship between the regulatory elements and pathways. Our interactome modeling took the advantage of modeling information in process pathways of Database for Annotation, Visualization and Integrated Discovery (DAVID), Gene ontology (GO) and KEGG (www.genome.jp/kegg), creating new global biological associations within the dataset.

\section{Declarations}

\section{Ethics approval and consent to participate}

Not applicable

\section{Consent for publication}

Not applicable.

\section{Availability of data and materials}

The datasets analyzed during the current study are available from multiple repositories (see accession numbers in Tables 1, 2, and 5). Additional accession numbers provided in supplementary Table 1 and 4.

\section{Competing interests}

Authors declare we have no competing financial or personal interest

\section{Funding}

No funding to declare.

\section{Authors' Contributions}

OBM and BNT conceptualized and designed the experiments; OBM, ART, NAS and AA carried out the experiments, analyzed the data and drafted the manuscript; ART, EM, BNT and OBM revised the 
manuscript, contributed to the discussion and scientific content. All authors read and approved the final version of the manuscript.

\section{Acknowledgements}

None

\section{Authors' information (optional)}

\section{References}

1. Lavon Y, Leitner G, Kressel Y, Ezra E, Wolfenson D. Comparing effects of bovine Streptococcus and Escherichia coli mastitis on impaired reproductive performance. J Dairy Sci. 2019;102(11):1058798.

2. Rault L, Lévêque P-A, Barbey S, Launay F, Larroque H, Le Loir Y, et al. Bovine teat cistern microbiota composition and richness are associated with the immune and microbial responses during transition to once-daily milking. Front Microbiol. 2020;11:602404.

3. McConnel CS, Crisp SA, Biggs TD, Ficklin SP, Parrish LM, Trombetta SC, et al. A fixed cohort field study of gene expression in circulating leukocytes from dairy cows with and without mastitis. Front Vet Sci. 2020;7:559279.

4. Khan MZ, Khan A, Xiao J, Ma J, Ma Y, Chen T, et al. Overview of research development on the role of NF-KB signaling in mastitis. Animals. 2020;10(9):1625.

5. Liu W, Wang X. Prediction of functional microRNA targets by integrative modeling of microRNA binding and target expression data. Genome Biol. 2019;20(1):18.

6. Tong C, Chen Q, Zhao L, Ma J, Ibeagha-Awemu EM, Zhao X. Identification and characterization of long intergenic noncoding RNAs in bovine mammary glands. BMC Genomics. 2017;18(1):468.

7. Morenikeji OB, Hawkes ME, Hudson AO, Thomas BN. Computational network analysis identifies evolutionarily conserved miRNA gene interactions potentially regulating immune response in bovine trypanosomosis. Front Microbiol. 2019;10:2010.

8. Wang H, Wang X, Li X, Wang Q, Qing S, Zhang Y, et al. A novel long non-coding RNA regulates the immune response in MAC -T cells and contributes to bovine mastitis. FEBS J. 2019;286(9):1780-95.

9. Li A, Mallik S, Luo H, Jia P, Lee D-F, Zhao Z. H19, a long non-coding RNA, mediates transcription factors and target genes through interference of microRNAs in pan-cancer. Molecular Therapy Nucleic Acids. 2020;21:180-91.

10. Dahariya S, Paddibhatla I, Kumar S, Raghuwanshi S, Pallepati A, Gutti RK. Long non-coding RNA: classification, biogenesis and functions in blood cells. Molecular Immunology. 2019;112:82-92.

11. Chen J, Wang Y, Wang C, Hu J-F, Li W. LncRNA functions as a new emerging epigenetic factor in determining the fate of stem cells. Front Genet. 2020;11:277. 
12. Ou-Yang L, Huang J, Zhang X-F, Li Y-R, Sun Y, He S, et al. LncRNA-disease association prediction using two-side sparse self-representation. Front Genet. 2019;10:476.

13. Yue B, Li H, Liu M, Wu J, Li M, Lei C, et al. Characterization of IncRNA-miRNA-mRNA network to reveal potential functional ceRNAs in bovine skeletal muscle. Front Genet. 2019;10:91.

14. Morenikeji OB, Bernard K, Strutton E, Wallace M, Thomas BN. Evolutionarily conserved Iong noncoding RNA regulates gene expression in cytokine storm during COVID-19. Front Bioeng Biotechnol. 2021;8:582953.

15. Li M, Sun X, Cai H, Sun Y, Plath M, Li C, Lan X, Lei C, Lin F, Bai Y, Chen H. Long non-coding RNA ADNCR suppresses adipogenic differentiation by targeting miR-204. Biochim Biophys Acta. 2016 Jul;1859(7):871-82.

16. Jiang M, Cheng Y, Wang D, Lu Y, Gu S, Wang C, et al. Transcriptional network modulated by the prognostic signature transcription factors and their long noncoding RNA partners in primary prostate cancer. EBioMedicine. 2020;63:103150.

17. Madsen JGS, Rauch A, Van Hauwaert EL, Schmidt SF, Winnefeld M, Mandrup S. Integrated analysis of motif activity and gene expression changes of transcription factors. Genome Res. 2018;28(2):243-55.

18. Hanif Q, Farooq M, Amin I, Mansoor S, Zhang Y, Khan QM. In silico identification of conserved miRNAs and their selective target gene prediction in indicine (Bos indicus) cattle. PLOS ONE 2018;13(10):e0206154.

19. Li J, Ma W, Zeng P, Wang J, Geng B, Yang J, et al. LncTar: a tool for predicting the RNA targets of long noncoding RNAs. Briefings in Bioinformatics. 2015;16(5):806-12.

20. Sticht C, Torre CDL, Parveen A, Gretz N. MiRWalk: an online resource for prediction of microRNA binding sites. PLOS ONE. 2018;13(10):e0206239.

21. Chang L, Zhou G, Soufan O, Xia J. MiRNet 2.0: network-based visual analytics for miRNA functional analysis and systems biology. Nucleic Acids Res. 2020;48(W1):W244-51.

22. Agarwal V, Bell GW, Nam J-W, Bartel DP. Predicting effective microRNA target sites in mammalian mRNAs. eLife 2015;4:e05005.

23. The Gene Ontology Consortium. The Gene Ontology Resource: 20 years and still GOing strong. Nucleic Acids Res. 2019;47(D1):D330-8.

24. Zhao Y, Li H, Fang S, Kang Y, wu W, Hao Y, et al. NONCODE 2016: an informative and valuable data source of long non-coding RNAs. Nucleic Acids Res. 2016;44:D203-8.

25. Cheng L, Wang P, Tian R, Wang S, Guo Q, Luo M, et al. LncRNA2Target v2.0: a comprehensive database for target genes of IncRNAs in human and mouse. Nucleic Acids Res. 2019;47:D140-4.

26. Abebe R, Hatiya H, Abera M, Megersa B, Asmare K. Bovine mastitis: prevalence, risk factors and isolation of Staphylococcus aureus in dairy herds at hawassa milk shed, South Ethiopia. BMC Veterinary Research. 2016;12(1):270. 
27. Heikkilä AM, Liski E, Pyörälä S, Taponen S. Pathogen-specific production losses in bovine mastitis. J Dairy Sci. 2018;101(10):9493-9504.

28. Skarbye AP, Krogh MA, Sørensen JT. The effect of individual quarter dry-off in management of subclinical mastitis on udder condition and milk production in organic dairy herds: a randomized field trial. J Dairy Sci. 2018;101(12):11186-98.

29. Sun C, Fu Y, Gu X, Xi X, Peng X, Wang C, et al. Macrophage-enriched IncRNA RAPIA: a novel therapeutic target for atherosclerosis. Arterioscler Thromb Vasc Biol. 2020;40(6):1464-78.

30. Li T, Lu H, Wang X, Gao Q, Dai Y, Shang J, et al. Molecular characteristics of Staphylococcus aureus causing bovine mastitis between 2014 and 2015. Front Cell Infect Microbiol. 2017;7:127.

31. Lin T, Yang Y, Ye X, Yao J, Zhou H. Low expression of miR-99b promotes progression of clear cell renal cell carcinoma by up-regulating IGF1R/Akt/mTOR signaling. Int J Clin Exp Pathol. 2020;13(12):3083-91.

32. Fang L, Hou Y, An J, Li B, Song M, Wang X, et al. genome-wide transcriptional and posttranscriptional regulation of innate immune and defense responses of bovine mammary gland to Staphylococcus aureus. Front Cell Infect Microbiol. 2016;6:193.

33. Bulgari O, Dong X, Roca AL, Caroli AM, Loor JJ. Innate immune responses induced by lipopolysaccharide and lipoteichoic acid in primary goat mammary epithelial cells. J Anim Sci Biotechnol. 2017;8:29.

34. Wang G, Zheng X, Zheng Y, Cao R, Zhang M, Sun Y, et al. Construction and analysis of the IncRNAmiRNA-mRNA network based on competitive endogenous RNA reveals functional genes in heart failure. Mol Med Rep 2019;19(2):994-1003.

35. Casas E, Cai G, Kuehn LA, Register KB, McDaneld TG, Neill JD. Association of microRNAs with antibody response to Mycoplasma bovis in Beef Cattle. PLOS ONE 2016;11(8):e0161651.

36. Ma S, Tong C, Ibeagha-Awemu EM, Zhao X. Identification and characterization of differentially expressed exosomal microRNAs in bovine milk infected with Staphylococcus aureus. BMC Genomics 2019;20(1):934.

37. Han S, Li X, Liu J, Zou Z, Luo L, Wu R, et al. Bta-miR-223 targeting CBLB contributes to resistance to Staphylococcus aureus mastitis through the PI3K/AKT/NF-KB pathway. Front Vet Sci. 2020;7.

38. Deny M, Romano M, Denis O, Casimir G, Chamekh M. Progressive control of streptococcus agalactiae-induced innate inflammatory response is associated with time course expression of microRNA-223 by neutrophils. Infection and Immunity. 2020;88:2.

39. Brook AC, Jenkins RH, Clayton A, Kift-Morgan A, Raby A-C, Shephard AP, et al. Neutrophil-derived miR223 as local biomarker of bacterial peritonitis. Sci Rep. 2019;9(1):10136.

40. Tay HL, Kaiko GE, Plank M, Li J, Maltby S, Essilfie A-T, et al. Antagonism of miR-328 increases the antimicrobial function of macrophages and neutrophils and rapid clearance of non-typeable haemophilus influenzae (NTHi) from infected lung. PLOS Pathogens 2015;11(4):e1004549.

41. Mendonça LS, Santos JM, Kaneto CM, de Carvalho LD, Lima-Santos J, Augusto DG, Carvalho SM, Soares-Martins JA, Silva-Jardim I. Characterization of serum cytokines and circulating microRNAs 
that are predicted to regulate inflammasome genes in cutaneous leishmaniasis patients. Experimental Parasitology. 2020 Mar 1;210:107846.

42. Khan R, Raza SHA, Junjvlieke Z, Xiaoyu W, Wang H, Cheng G, et al. Bta-miR-149-5p inhibits proliferation and differentiation of bovine adipocytes through targeting CRTCs at both transcriptional and posttranscriptional levels. J of Cell Physiol. 2020;235.

43. Guo L, Zhao Y, Yang S, Zhang H, Chen F. An integrated analysis of miRNA, IncRNA, and mRNA expression profiles. Sci Rep. 2017;7:44026.

44. Zhang S, Kang Z, Cai H, Jiang E, Pan C, Dang R, et al. Identification of novel alternative splicing of bovine IncRNA IncFAM200B and its effects on preadipocyte proliferation. J Cell Physiol. 2021;236(1):601-11.

45. Li N, Wu S, Yu L. The associations of long non-coding RNA taurine upregulated gene 1 and microRNA-223 with general disease severity and mortality risk in sepsis patients. Medicine. 2020;99(50):e23444.

46. Li L, Huang J, Zhang X, Ju Z, Qi C, Zhang Y, et al. One SNP in the 3'-UTR of HMGB1 gene affects the binding of target bta-miR-223 and is involved in mastitis in dairy cattle. Immunogenetics. 2012;64(11):817-24.

47. Black AR, Black JD, Azizkhan-Clifford J. Sp1 and krüppel-like factor family of transcription factors in cell growth regulation and cancer. J of Cell Physiol. 2001;188(2):143-60.

48. Wierstra I. Sp1: emerging roles-beyond constitutive activation of TATA-less housekeeping genes. Biochemical and Biophysical Research Communications. 2008;372(1):1-13.

49. Zenz R, Scheuch $H$, Martin P, Frank C, Eferl R, Kenner L, et al. C-Jun regulates eyelid closure and skin tumor development through EGFR signaling. Developmental Cell. 2003;4(6):879-89.

50. Liu T, Zhang L, Joo D, Sun S-C. NF-KB signaling in inflammation. Signal Transduct Target Ther. 2017;2:17023.

51. Wu J, Li L, Sun Y, Huang S, Tang J, Yu P, et al. Altered Molecular Expression of the TLR4/NF-KB Signaling Pathway in Mammary Tissue of Chinese Holstein Cattle with Mastitis. PLOS ONE. 2015;10(2).

52. Wen AY, Sakamoto KM, Miller LS. The Role of the Transcription Factor CREB in Immune Function. The Journal of Immunology. 2010;185(11):6413-9.

53. Burimuah V, Sylverken A, Owusu M, El-Duah P, Yeboah R, Lamptey J, et al. Molecular-based crossspecies evaluation of bovine coronavirus infection in cattle, sheep and goats in Ghana. BMC Veterinary Research. 2020;16(1):405.

54. Morenikeji OB, Wallace M, Strutton E, Bernard K, Yip E, Thomas BN. Integrative network analysis of predicted miRNA-targets regulating expression of immune response genes in bovine coronavirus infection. Front Genet. 2020;11:584392.

55. Buza N, Xu F, Wu W, Carr RJ, Li P, Hui P. Recurrent chromosomal aberrations in intravenous leiomyomatosis of the uterus: high-resolution array comparative genomic hybridization study. Hum Pathol. 2014;45(9):1885-92. 
56. Szklarczyk D, Gable AL, Lyon D, Junge A, Wyder S, Huerta-Cepas J, et al. STRING v11: protein-protein association networks with increased coverage, supporting functional discovery in genome-wide experimental datasets. Nucleic Acids Res. 2019;47(D1):D607-13.

57. Hu H, Miao Y-R, Jia L-H, Yu Q-Y, Zhang Q, Guo A-Y. AnimalTFDB 3.0: a comprehensive resource for annotation and prediction of animal transcription factors. Nucleic Acids Res. 2019;47(D1):D33-8.

58. Matys V, Kel-Margoulis OV, Fricke E, Liebich I, Land S, Barre-Dirrie A, Reuter I, Chekmenev D, Krull M, Hornischer K, Voss N, Stegmaier P, Lewicki-Potapov B, Saxel H, Kel AE, Wingender E. TRANSFAC and its module TRANSCompel: transcriptional gene regulation in eukaryotes. Nucleic Acids Res. 2006;34(Database issue):D108-110.

59. Medina IR, Lubovac-Pilav Z. Gene co-expression network analysis for identifying modules and functionally enriched pathways in type 1 diabetes. PLOS ONE. 2016;11(6):e0156006.

60. Jiao X, Sherman B, Huang da W, Stephens R, Baseler M, Lane H, et al. DAVID-WS: a stateful web service to facilitate gene/protein list analysis. Bioinformatics. 2012;28(13):1805-6.

61. Kozomara A, Birgaoanu M, Griffiths-Jones S. MiRBase: from microRNA sequences to function. Nucleic Acids Res. 2019;47:D155-62.

62. Kumar S, Stecher G, Li M, Knyaz C, Tamura K. MEGA X: Molecular Evolutionary Genetics Analysis across Computing Platforms. Mol Biol Evol. 2018;35(6):1547-9.

63. Corpet F. Multiple sequence alignment with hierarchical clustering. Nucleic Acids Res. 1988;16(22):10881-90.

64. Letunic I, Bork P. Interactive Tree of Life (iTOL) v4: recent updates and developments. Nucleic Acids Res. 2019;47(W1):W256-W259.

65. Luo X, Tu T, Zhong Y, Xu S, Chen X, Chen L, et al. CeRNA network analysis shows that IncRNA CRNDE promotes progression of glioblastoma through sponge mir-9-5p. Front Genet. 2021;12:617350.

\section{Tables}

Table 1. List of candidate bovine mastitis genes and their accession number, genomic location, and strand type. 


\begin{tabular}{|llll|}
\hline Candidate Gene & Accession Number & Genomic Location & Strand (+/-) \\
\hline MYD88 & NM_001014382 & 22:11625515-11629955 & + \\
\hline CD4 & NM_001103225 & $5: 103631360-103654878$ & - \\
\hline IL-10 & NM_174088 & $16: 4550836-4555318$ & - \\
\hline IFNY & NM_174086 & $5: 45624462-45629336$ & + \\
\hline IL-4 & NM_173921 & $7: 21696248-21704136$ & - \\
\hline ICAM1 & NM_174348 & $7: 14787173-14797855$ & + \\
\hline CXCL8 & NM_173925 & $6: 88810418-88814572$ & + \\
\hline TLR4 & NM_174198 & $8: 107057826-107068836$ & + \\
\hline TNFa & NM_173966 & $23: 27716168-27719047$ & - \\
\hline IL-18 & NM_174091 & $15: 22475988-22502331$ & - \\
\hline TLR2 & NM_174197 & $17: 3954019-3967242$ & - \\
\hline CD86 & NM_001038017 & $1: 66543642-66610926$ & + \\
\hline CCL2 & NM_174006 & $19: 15902777-15905368$ & - \\
\hline IL-6 & NM_173923 & $4: 31454749-31459131$ & + \\
\hline CSF2 & NM_174027 & $7: 22398938-22401303$ & - \\
\hline CD14 & NM_174008 & $7: 51762895-51765768$ & - \\
\hline
\end{tabular}

Table 2. Significant miRNA predicted by all three software and their mRNA sequence, accession number, genomic location, strand type and length. 


\begin{tabular}{|c|c|c|c|c|c|}
\hline miRNA & mRNA Sequence & Accession & $\begin{array}{l}\text { Genomic } \\
\text { Location }\end{array}$ & $\begin{array}{l}\text { Strand } \\
(+/-)\end{array}$ & $\begin{array}{l}\text { Length } \\
\text { (bp) }\end{array}$ \\
\hline $\begin{array}{l}\text { bta- } \\
\text { miR- } \\
149-5 p\end{array}$ & UCUGGCUCCGUGUCUUCACUCCC & MI0021115 & $\begin{array}{l}3: 120921662- \\
120921751\end{array}$ & + & 23 \\
\hline $\begin{array}{l}\text { bta- } \\
\text { miR- } \\
185\end{array}$ & UGGAGAGAAAGGCAGUUCCUGA & MI0009758 & $\begin{array}{l}\text { 17: } \\
75173467- \\
75173545\end{array}$ & + & 22 \\
\hline $\begin{array}{l}\text { bta- } \\
\text { miR- } \\
223\end{array}$ & UGUCAGUUUGUCAAAUACCCCA & MI0009782 & $\begin{array}{l}X: \\
94,562,822- \\
94,562,929\end{array}$ & - & 22 \\
\hline $\begin{array}{l}\text { bta- } \\
\text { miR-24- } \\
3 p\end{array}$ & UGGCUCAGUUCAGCAGGAACAG & MIMAT0003840 & - & - & 22 \\
\hline $\begin{array}{l}\text { bta- } \\
\text { miR- } \\
328\end{array}$ & CUGGCCCUCUCUGCCCUUCCGU & MI0009800 & $\begin{array}{l}\text { 18: } \\
35062240- \\
35062331\end{array}$ & - & 22 \\
\hline $\begin{array}{l}\text { bta- } \\
\text { miR- } \\
874\end{array}$ & CUGCCCUGGCCCGAGGGACCGA & MI0009900 & $\begin{array}{l}\text { 7: } 50886238- \\
50886313\end{array}$ & - & 22 \\
\hline
\end{tabular}

These miRNAs are from the Venn diagram generated through the overlap of the three softwares-miRWalk, miRNet an TargetScan

Table 3. Significant IncRNA predicted to target the most candidate genes 


\begin{tabular}{|c|c|c|}
\hline List of IncRNA & $\begin{array}{l}\text { Number of } \\
\text { target genes }\end{array}$ & List of target genes \\
\hline NONBTAT001181.2 & 16 & $\begin{array}{l}\text { MYD88, CD4, IFNy, IL-4, ICAM1, IL-18, CD86, CSF2, CCL2, } \\
\text { TLR4, CXCL8, IL-10, IL-6, CD14, TLR2, TNFa }\end{array}$ \\
\hline XR_003029725.1 & 16 & $\begin{array}{l}\text { MYD88, CD4, IFNy, IL-4, ICAM1, IL-18, CD86, CSF2, CCL2, } \\
\text { TLR4, CXCL8, IL-10, IL-6, CD14, TLR2, TNFa }\end{array}$ \\
\hline NONBTAT010129.2 & 16 & $\begin{array}{l}\text { MYD88, CD4, IFNy, IL-4, ICAM1, IL-18, CD86, CSF2, CCL2, } \\
\text { TLR4, CXCL8, IL-10, IL-6, CD14, TLR2, TNFa }\end{array}$ \\
\hline XR_003030515.1 & 16 & $\begin{array}{l}\text { MYD88, CD4, IFNy, IL-4, ICAM1, IL-18, CD86, CSF2, CCL2, } \\
\text { TLR4, CXCL8, IL-10, IL-6, CD14, TLR2, TNFa }\end{array}$ \\
\hline XR_003033296.1 & 16 & $\begin{array}{l}\text { MYD88, CD4, IFNy, IL-4, ICAM1, IL-18, CD86, CSF2, CCL2, } \\
\text { TLR4, CXCL8, IL-10, IL-6, CD14, TLR2, TNFa }\end{array}$ \\
\hline NONBTAT027932.1 & 16 & $\begin{array}{l}\text { MYD88, CD4, IFNy, IL-4, ICAM1, IL-18, CD86, CSF2, CCL2, } \\
\text { TLR4, CXCL8, IL-10, IL-6, CD14, TLR2, TNFa }\end{array}$ \\
\hline XR_234647.4 & 13 & $\begin{array}{l}\text { MYD88, CD4, IFNy, IL-4, ICAM1, IL-18, CSF2, TLR4, CXCL8, IL- } \\
\text { 10, CD14, TLR2, TNFa }\end{array}$ \\
\hline NONBTAT013032.2 & 13 & $\begin{array}{l}\text { MYD88, CD4, ICAM1, IL-18, CD86, CSF2, CCL2, TLR4, CXCL8, } \\
\text { IL-10, CD14, TLR2, TNFa }\end{array}$ \\
\hline
\end{tabular}

Table 4. Gene Ontology biological processes, molecular functions, and cellular components of bovine mastitis target genes 
GO biological process

LPS-mediated signaling pathway

myeloid leukocyte activation

positive regulation of interleukin-8 production

regulation of interleukin-8 production

positive regulation of interleukin-6 production

regulation of interleukin-23 production

regulation of cytokine secretion

positive regulation of tyrosine phosphorylation of STAT protein
Gene (s)

Raw p-

value

CCL2, TLR4, MYD88, CD14, IL- $2.58 \mathrm{E}-$ 18, TNFa
IL-4, IFNy, TLR4, CXCL8, IL-18, CSF2, TNFa
$4.92 \mathrm{E}-$

13

$1.30 \mathrm{E}-$

12
6, TNFa

TLR2, TLR4, MYD88, CD14, IL

$6, \mathrm{TNFa}$

$6.92 \mathrm{E}-$

12
TLR2, IFNy, TLR4, MYD88, IL6, TNFa
2.01E11

IFNy, TLR4, MYD88, CSF2

1.34E-

10

TLR2, IFNy, CD14, IL-10, TNFa

$2.50 \mathrm{E}-$ 10

IL-4, IFNy, IL-6, IL-18, CSF2

4.67E10

positive regulation of NIK/NF-kappaB signaling

regulation of chemokine production

regulation of tyrosine phosphorylation of STAT protein

positive regulation of cytokine production involved in inflammatory response

positive regulation of cytokine secretion

regulation of interleukin-17 production
TLR2, TLR4, CD14, IL-18, $\mathrm{TNFa}$ $5.65 \mathrm{E}-$ 10

TLR2, TLR4, MYD88, IL-6, $\mathrm{TNFa}$

8.12E-

10

IL-4, IFNy, IL-6, IL-18, CSF2

1.14E09

TLR4, MYD88, IL-6, TNFa 4.01E09

IFNy, CD14, IL-10, TNFa

4.70E09

IFNy, TLR4, MYD88, IL-18

$6.36 \mathrm{E}-$ 09 
positive regulation of tumor necrosis factor superfamily cytokine production

IFNy, TLR4, MYD88, CD14

regulation of cytokine production involved in inflammatory response

TLR4, MYD88, IL-6, TNFa

regulation of chemokine ( $\mathrm{C}-\mathrm{X}-\mathrm{C}$ motif) ligand 2 production

\section{GO molecular function}

Gene (s)

Raw pvalue

$$
\mathrm{NAD}(\mathrm{P})+\text { nucleosidase activity }
$$

TLR2, TLR4

$N A D+$ nucleotidase, cyclic ADP-ribose generating

TLR2, TLR4

$N A D+$ nucleosidase activity

TLR2, TLR4

Toll-like receptor binding

TLR2, MYD88 
GO cellular component

LPS receptor complex

phagocytic cup
Gene (s)

TLR4, CD14

TLR4, TNFa
Raw pvalue

$8.80 \mathrm{E}-$ 06

1.47E04

Table 5: List of transcription factors predicted by AnimalTFDB and GeneXplain, their genomic location and strands. 


\begin{tabular}{|c|c|c|c|}
\hline $\begin{array}{l}\text { COMMON TFs from the TWO } \\
\text { Database }\end{array}$ & Accession Number & Genomic Location & $\begin{array}{l}\text { Strand } \\
(+/-)\end{array}$ \\
\hline BCL6 & ENSBTAG00000001511 & $\begin{array}{l}1: 79557257- \\
79612240\end{array}$ & $(-)$ \\
\hline CREB1 & ENSBTAG00000005474 & $\begin{array}{l}2: 95845037- \\
95898849\end{array}$ & $(-)$ \\
\hline FOXA2 & ENSBTAG00000012407 & $\begin{array}{l}\text { 13:41542415- } \\
41547044\end{array}$ & $(-)$ \\
\hline FOXM1 & ENSBTAG00000015875 & $\begin{array}{l}5: 106886408- \\
106900942\end{array}$ & $(-)$ \\
\hline JUN & ENSBTAG00000004037 & $\begin{array}{l}\text { 3:87265922- } \\
87268047\end{array}$ & $(-)$ \\
\hline GATA1 & ENSBTAG00000003184 & $\begin{array}{l}\text { X:86899691- } \\
86906632\end{array}$ & $(-)$ \\
\hline HSF1 & ENSBTAG00000020751 & 14:612908-634769 & $(+)$ \\
\hline IRF1 & ENSBTAG00000031231 & $\begin{array}{l}7: 21938453- \\
21946840\end{array}$ & $(+)$ \\
\hline SP1 & ENSBTAG00000003021 & $\begin{array}{l}5: 26607078- \\
26643492\end{array}$ & $(+)$ \\
\hline SP2 & ENSBTAG00000013740 & $\begin{array}{l}\text { 19:38533093- } \\
38565741\end{array}$ & $(+)$ \\
\hline SMAD1 & ENSBTAG00000002835 & $\begin{array}{l}17: 12739131- \\
12825260\end{array}$ & $(+)$ \\
\hline TBP & ENSBTAG00000007686 & $\begin{array}{l}9: 104096534- \\
104106636\end{array}$ & $(-)$ \\
\hline TCF12 & ENSBTAG00000002586 & $\begin{array}{l}10: 53023683- \\
53085010\end{array}$ & $(-)$ \\
\hline ZNF143 & ENSG00000166478 & 11:9458955-9529888 & $(-)$ \\
\hline ZNF274 & ENSBTAG00000013353 & $\begin{array}{l}18: 65546272- \\
65569269\end{array}$ & $(-)$ \\
\hline ZNF384 & ENSBTAG00000017072 & $\begin{array}{l}5: 103755842- \\
103776263\end{array}$ & $(-)$ \\
\hline ZNF92 & ENSG00000146757 & $\begin{array}{l}7: 65373253- \\
65401682\end{array}$ & $(-)$ \\
\hline
\end{tabular}

Table 6. Gene Ontology biological processes, molecular functions, and cellular components of predicted TFs. 


\begin{tabular}{|llc|}
\hline GO biological process & TFs & \multicolumn{1}{c|}{$\begin{array}{c}\text { Raw p- } \\
\text { value }\end{array}$} \\
\hline Positive regulation by host of viral transcription & JUN, SP1 & $5.94 \mathrm{E}-05$ \\
\hline Regulation of regulatory T cell differentiation & BCL6, IRF1 & $1.11 \mathrm{E}-04$ \\
\hline Negative regulation of cell aging & FOXM1, BCL6 & $1.37 \mathrm{E}-04$ \\
\hline GO molecular function & & \\
\hline $\begin{array}{l}\text { Intronic transcription regulatory region sequence-specific DNA } \\
\text { binding }\end{array}$ & BCL6, HSF1 & 4.31E-05 \\
\hline cAMP response element binding & JUN, CREB1 & 7.83E-05 \\
\hline & & \\
\hline G0 cellular component & & \\
\hline Euchromatin & JUN, SP1, & 1.11E-06 \\
\hline
\end{tabular}

\section{Figures}


(a)
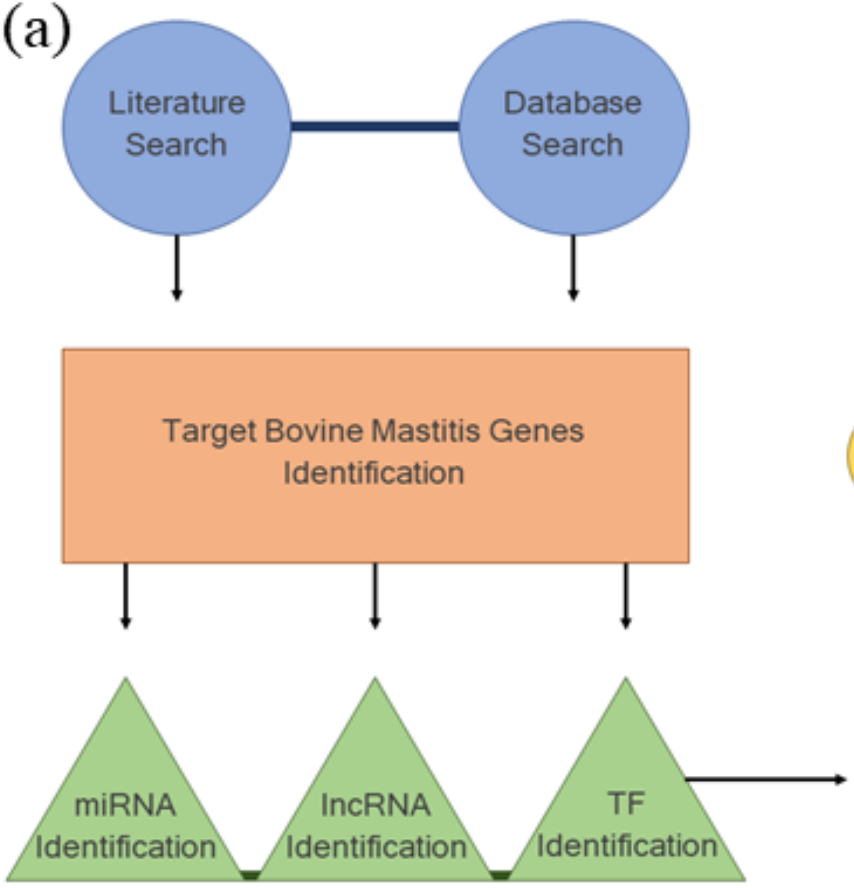

(b)

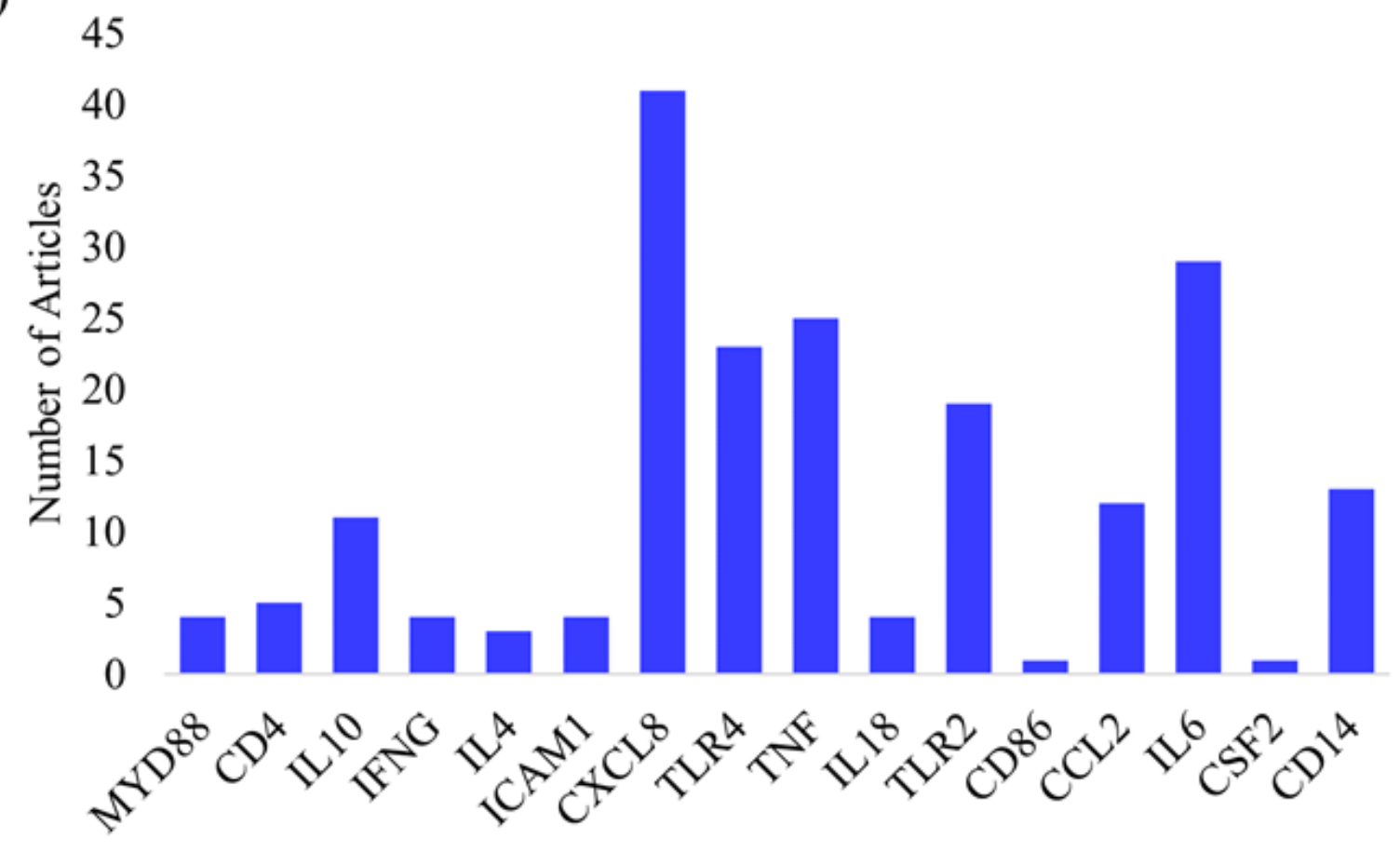

\section{Figure 1}

Flowchart of project steps and analysis procedures $(A)$ and number of articles mentioning each of the 16 target bovine mastitis genes (B). 


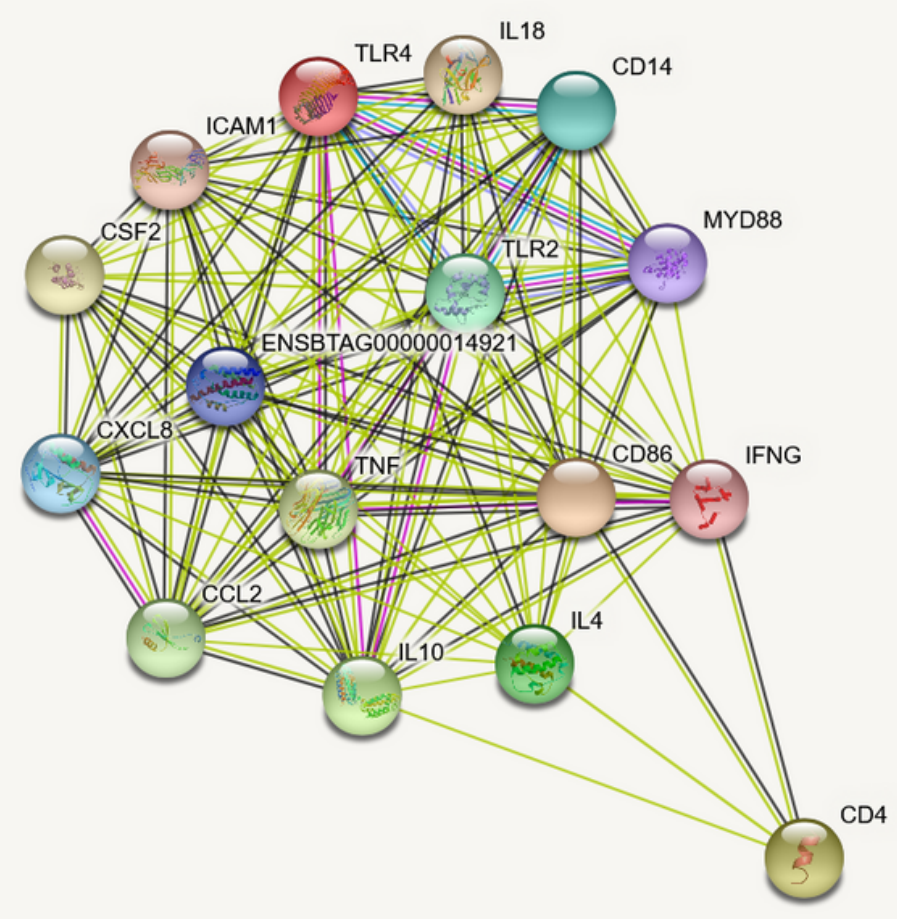

Figure 2

Network of 16 target bovine mastitis genes created using STRING. The Ensembl ID in the network refers to IL-6. 

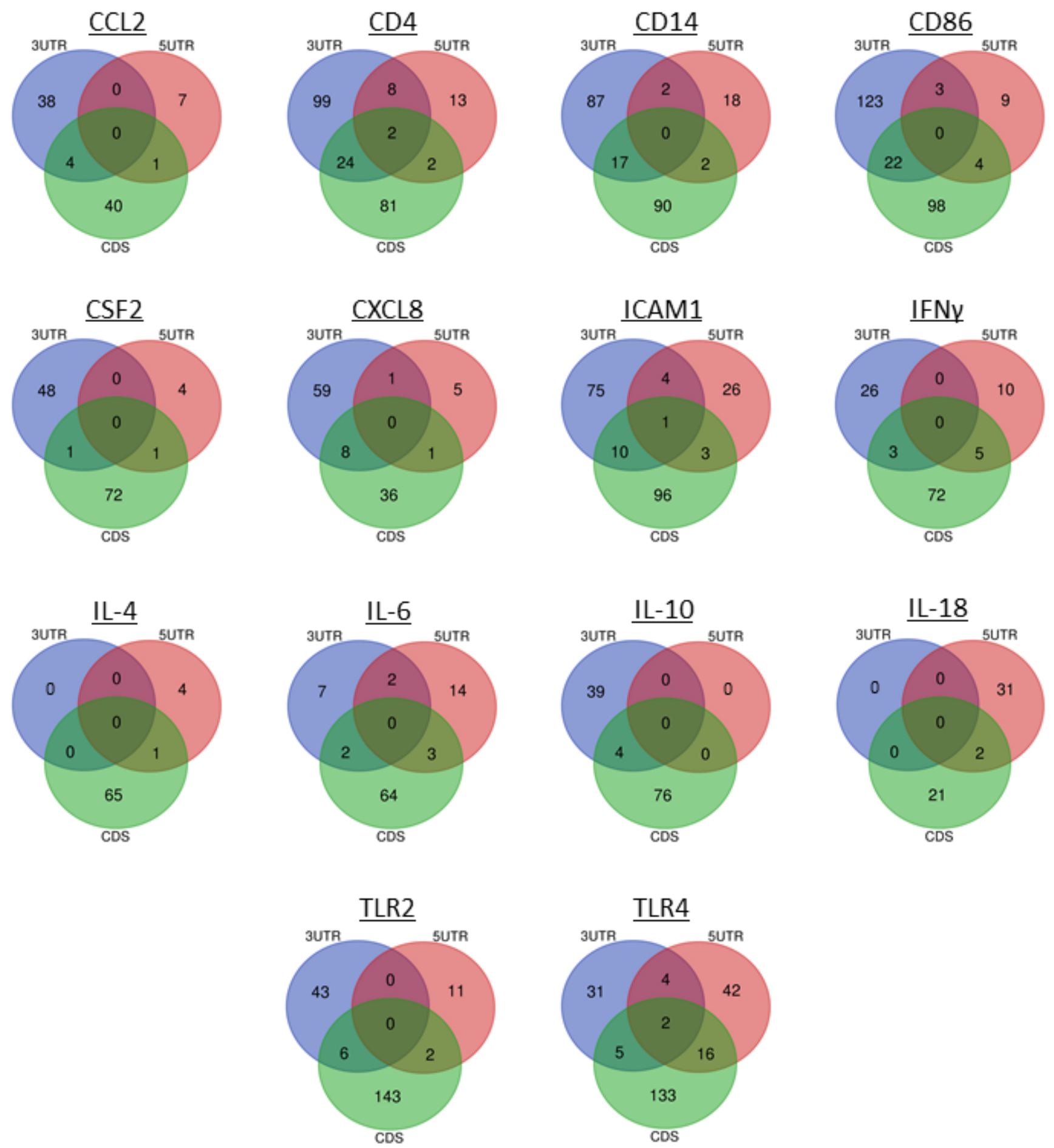

\section{Figure 3}

Venn Diagrams for 14 out of 16 target bovine mastitis genes showing the number of miRNA binding to the 3' UTR, CDS, and 5' UTR. The middle region of each diagram represents miRNA that bind to all three regions of the target gene. 
7

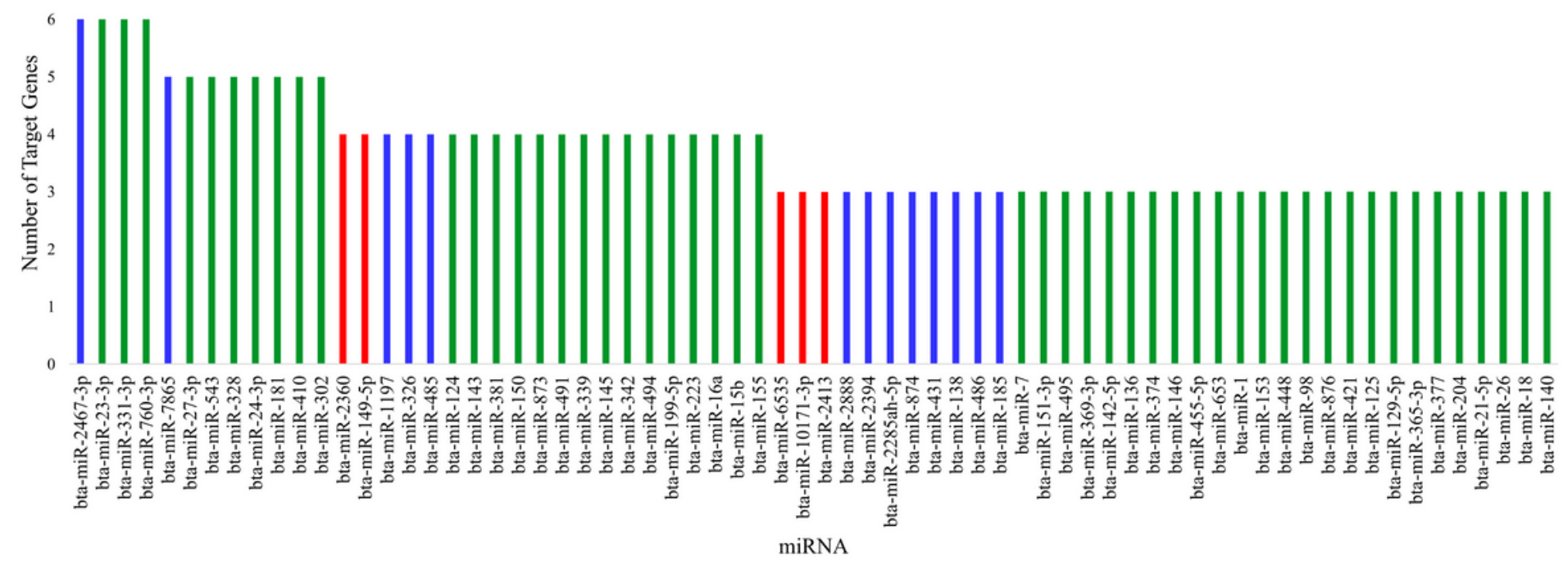

Figure 4

miRNA predicted to bind to three or more target genes. The red bars are miRNA predicted to bind to $3^{\prime}$ UTR, CDS, and 5' UTR. The blue bars represent miRNA binding to two of the three regions. The green bars are miRNA predicted to bind to one of the three regions. 


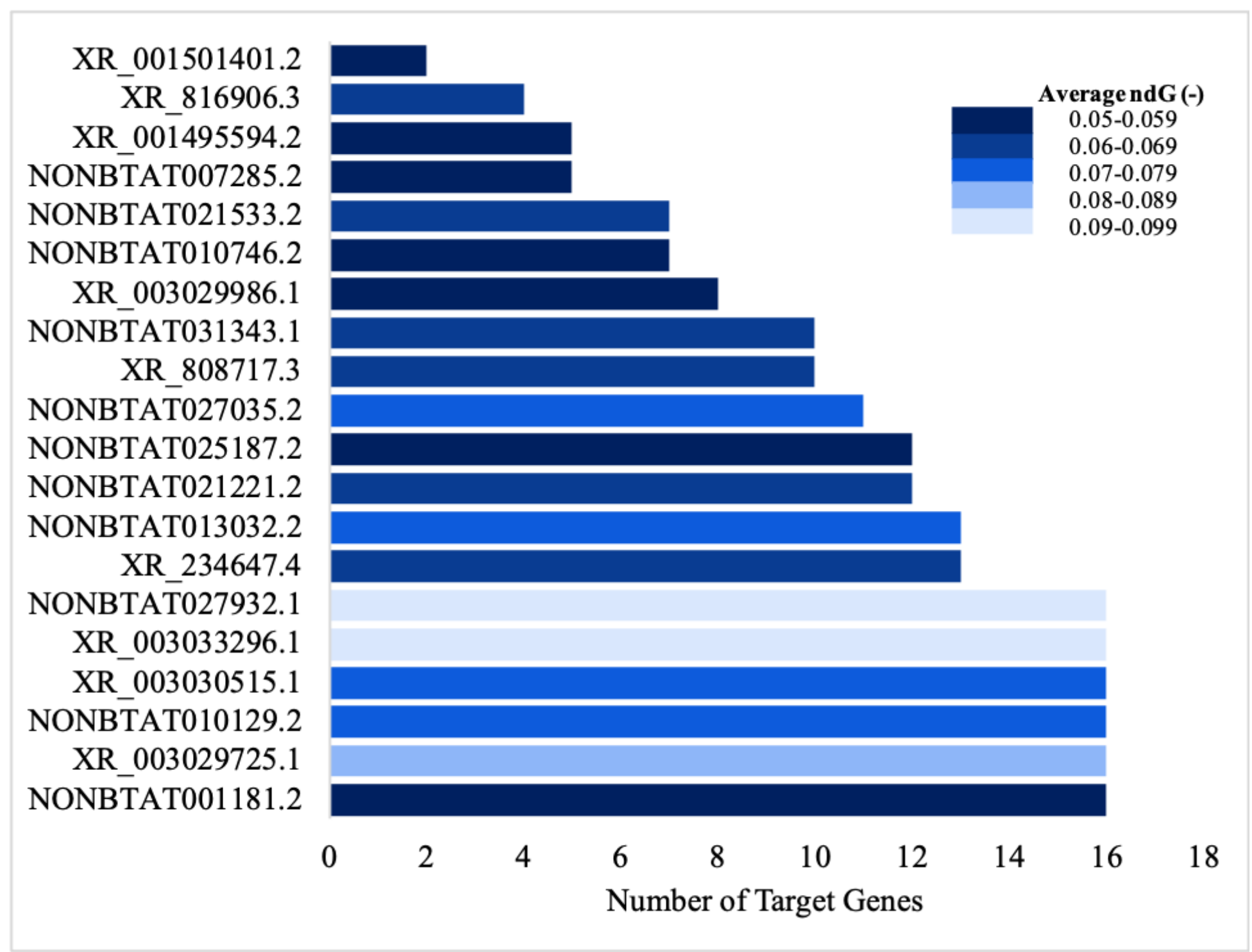

Figure 5

The 20 IncRNA and the number of target genes they are predicted to bind to. The darkest shade of blue corresponds to the lowest (-) ndG and the lightest shade of blue corresponds to the highest (-) ndG. 
(a) vascular endothelial GF production
regulation of $\mathrm{CCL} 2$ production
response to LTA
cellular response to LTA
positive regulation of IL-23 production
TLR signaling pathway regulation of cytokine production involved in inflammatory response positive regulation of TNF superfamily cytokine production positive regulation of chemokine production regulation of nitric oxide biosynthetic process macrophage activation regulation of IL-17 production positive regulation of cytokine secretion positive regulation of cytokine production involved in inflammatory response regulation of IL-23 production regulation of tyrosine phosphorylation of STAT protein regulation of chemokine production positive regulation of NIK/NF- $\mathrm{kB}$ signaling positive regulation of tyrosine phosphorylation of STAT protein regulation of cytokine secretion regulation of cytokine secretion
positive regulation of IL-6 production
regulation of IL-8 production
positive regulation of IL-8 production
LPS-mediated signaling pathway
myeloid leukocyte activation regulation of cytokine secretion
positive regulation of IL-6 production
regulation of IL-8 production
positive regulation of IL-8 production
LPS-mediated signaling pathway
myeloid leukocyte activation regulation of cytokine secretion
positive regulation of IL-6 production
regulation of IL-8 production
positive regulation of IL-8 production
LPS-mediated signaling pathway
myeloid leukocyte activation regulation of cytokine secretion
positive regulation of IL-6 production
regulation of IL-8 production
positive regulation of IL-8 production
LPS-mediated signaling pathway
myeloid leukocyte activation

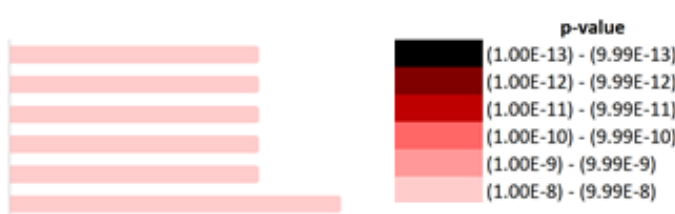
0 2 4
Number of Target Genes $6 \quad 8$

(b)

NOD-like receptor signaling pathway

Allograft rejection

Pertussis

Leishmaniasis

African trypanosomiasis

Salmonella infection

Inflammatory bowel disease

Legionellosis

Rheumatoid arthritis

Malaria

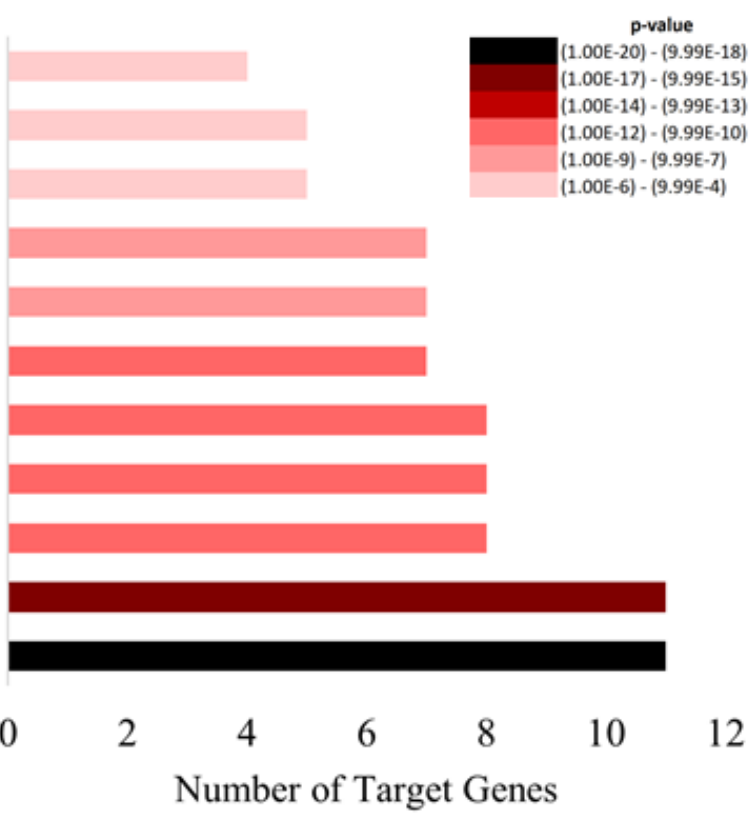

\section{Figure 6}

The biological processes and the number of target bovine mastitis genes involved (A) and the pathways and the corresponding number of target genes (B). In both Fig $6 \mathrm{a}$ and Fig $6 \mathrm{~b}$, the black bars indicate biological processes/pathways predicted with the lowest $\mathrm{p}$-value and the lightest red bar represent predictions with the greatest p-value. 


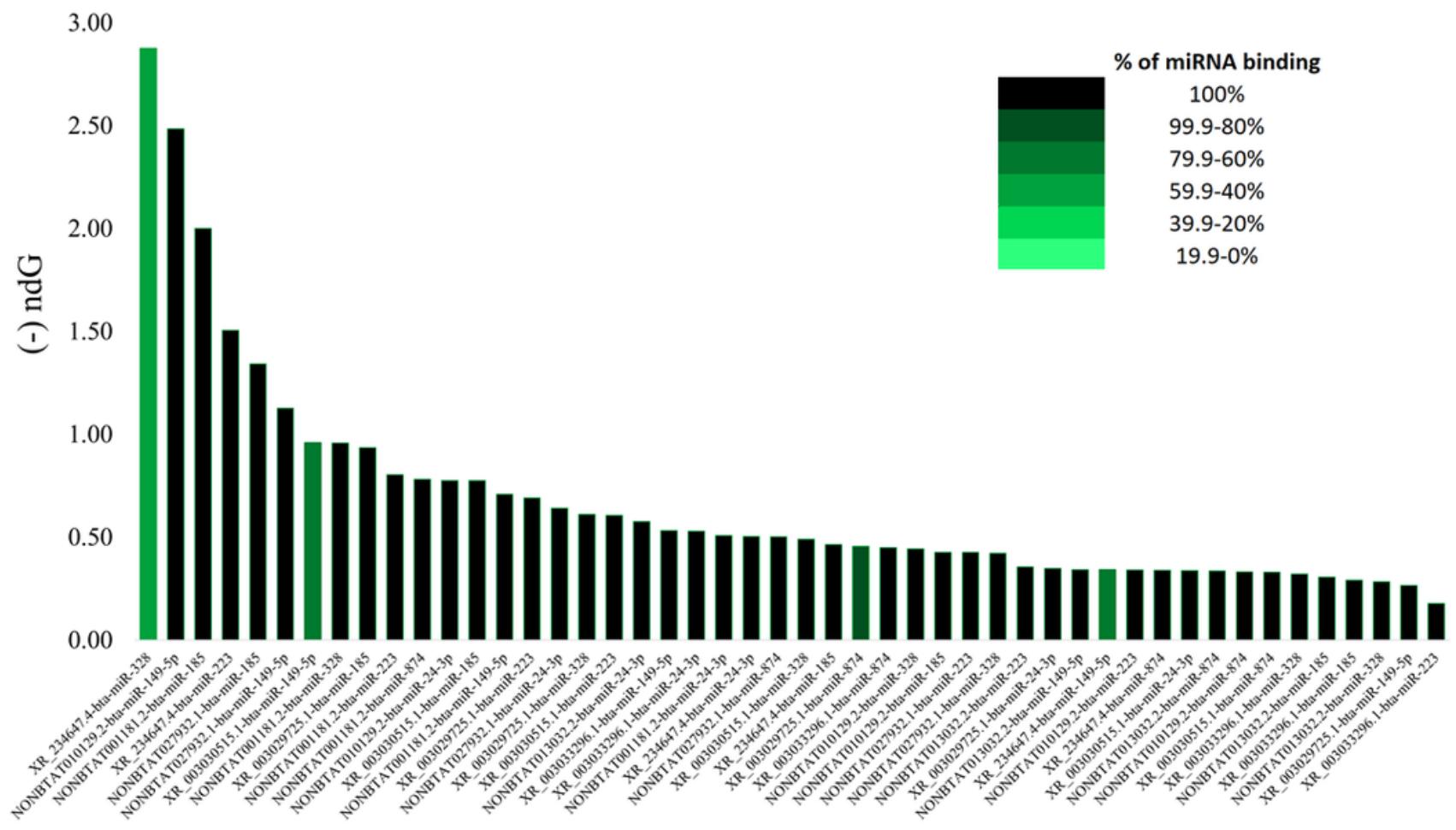

Figure 7

miRNA-IncRNA predicted binding with their normalized binding free energy (ndG). The black bars indicate the entire miRNA binds to the IncRNA and the lighter the green bar, the less complementary basing between miRNA and IncRNA.

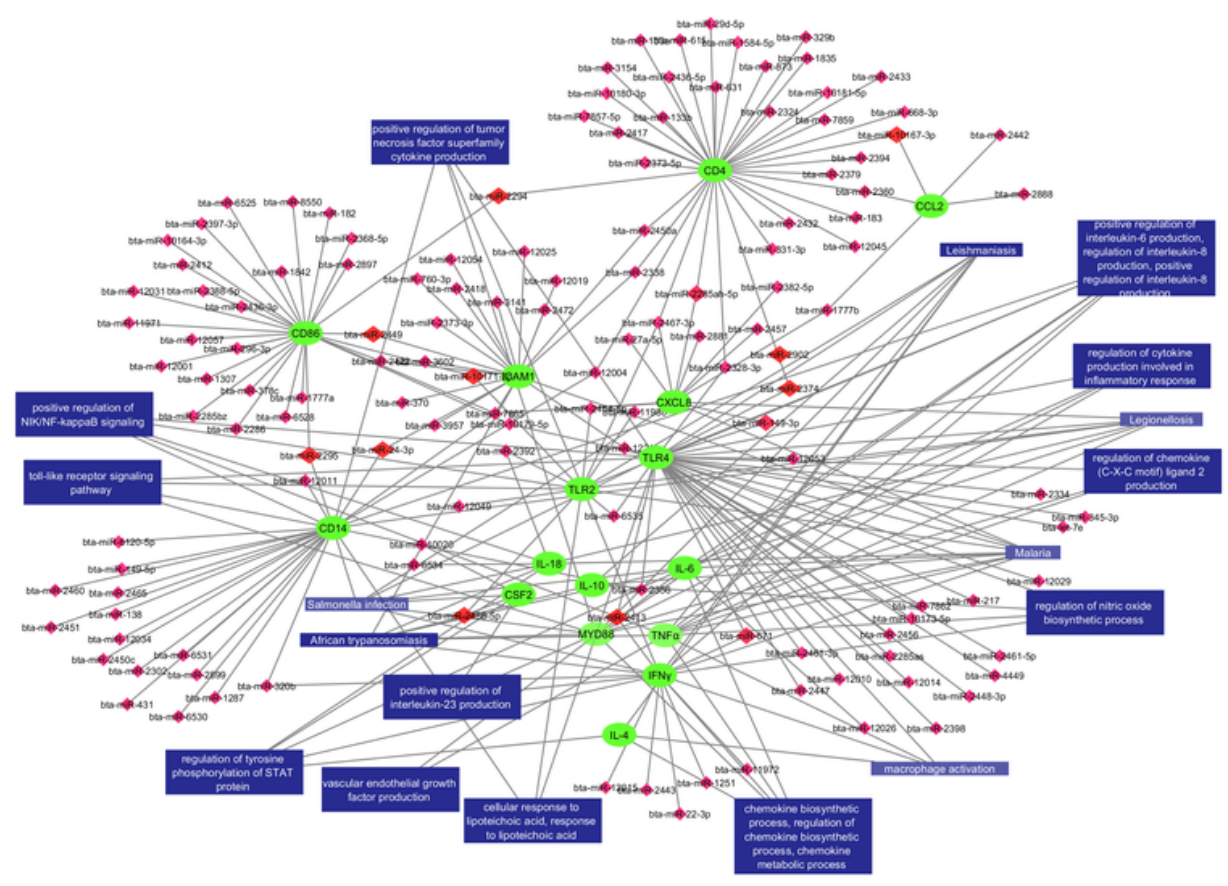

Figure 8 
Network interactome of miRNA, their target genes, and the gene ontologies of the target genes. The pink diamonds are miRNA binding to a single target gene while the red diamonds are miRNA binding to two or more target genes. The green circles are the 16 target genes and the blue rectangles are the biological processes, molecular functions, cellular components, and pathways.

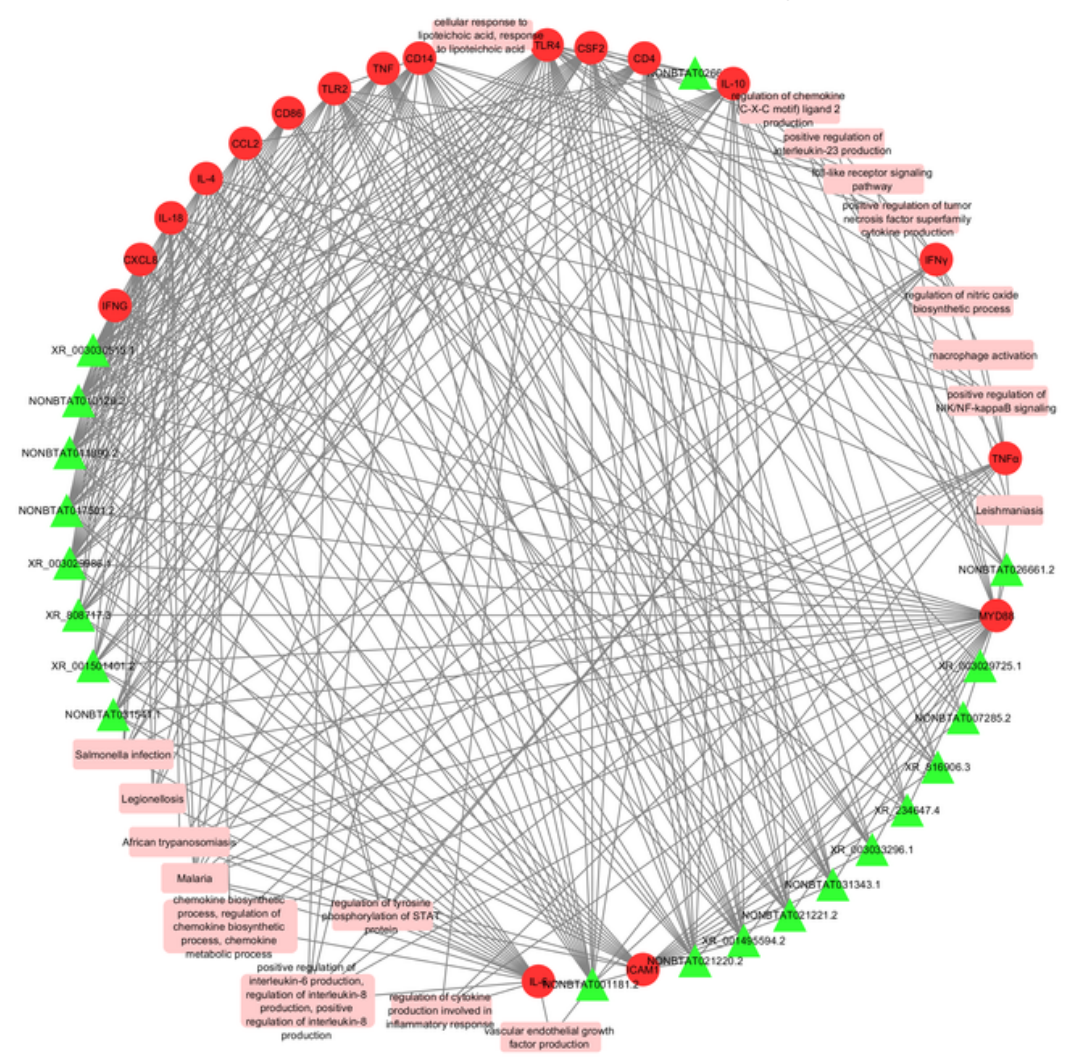

\section{Figure 9}

A network incorporating IncRNA, their target genes and corresponding gene ontologies. The green triangles are the IncRNA, red circles represent the target bovine mastitis genes, and the pink rectangles are the biological processes, molecular functions, cellular components, and pathways. 


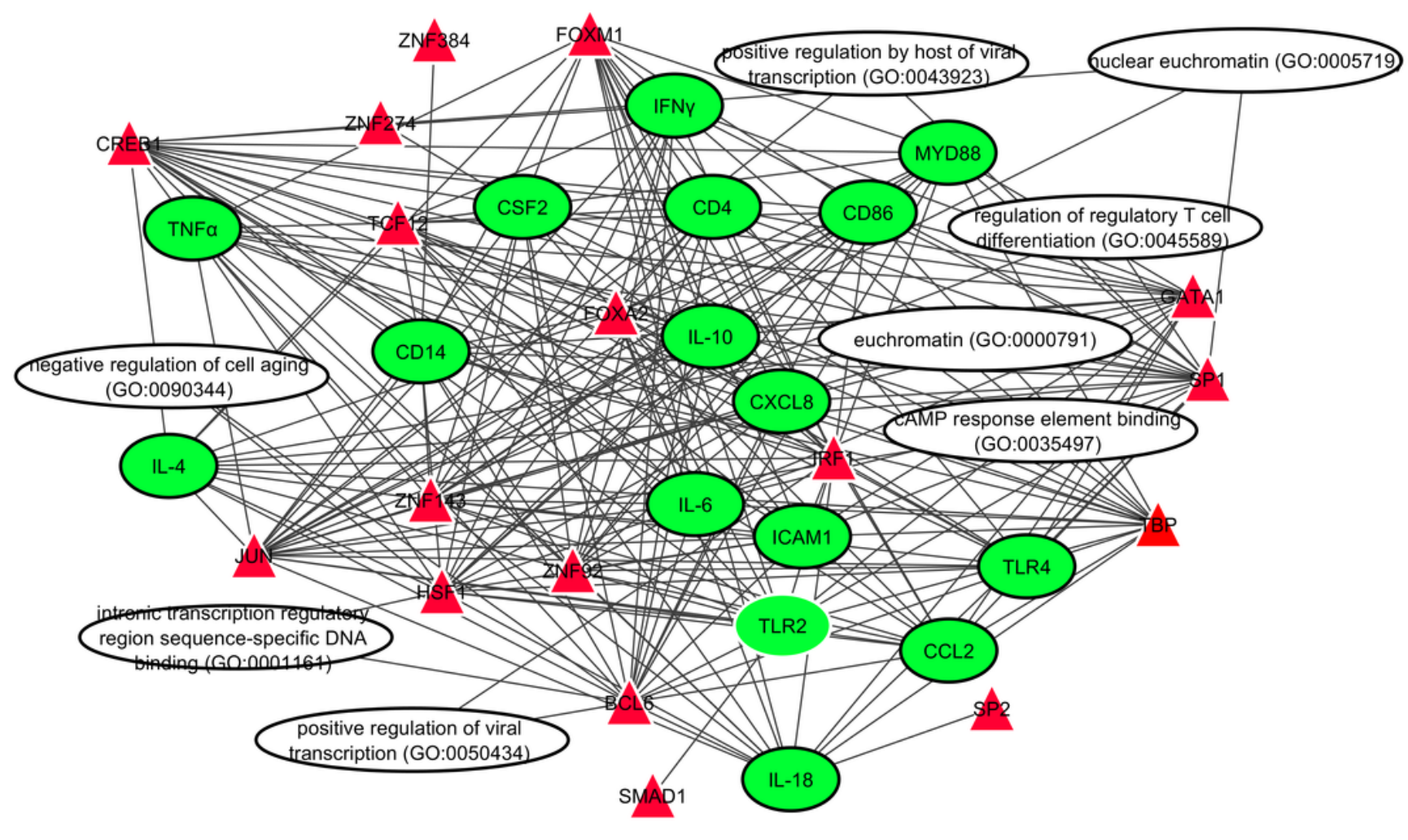

Figure 10

Network interactome of TFs, bovine mastitis target genes, and gene ontologies. The red triangles are TFs while the green circles are the target bovine mastitis genes. The while ovals represent the biological processes, molecular functions, cellular components, and pathways. 


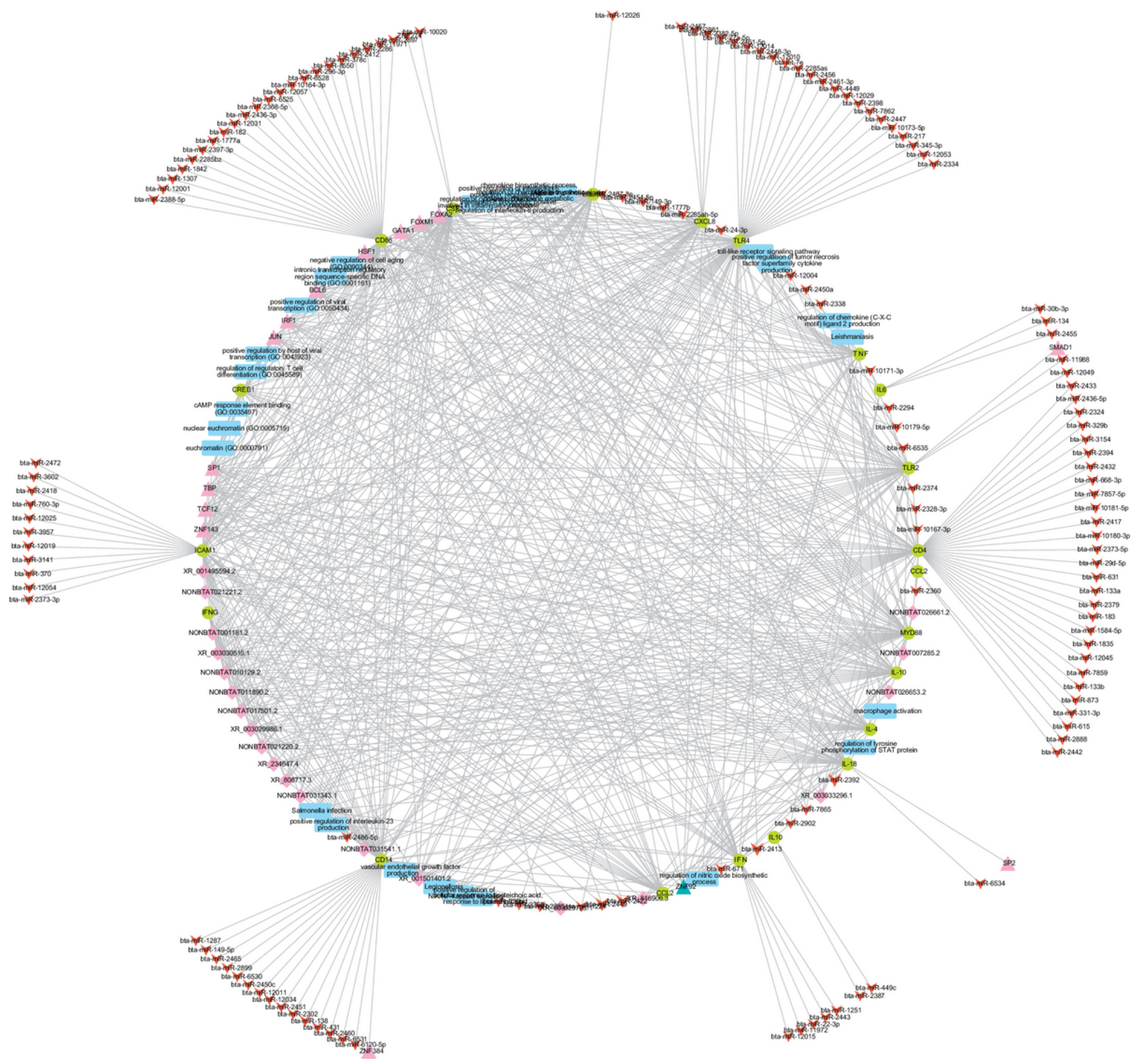

Figure 11

A network incorporating miRNA, IncRNA, TFs, target genes, and gene ontologies. The red arrowheads represent miRNA, the purple diamonds IncRNA, the teal triangles TFs, the green circles target genes, and the blue rectangles biological processes, molecular functions, cellular components, and pathways.

\section{Supplementary Files}

This is a list of supplementary files associated with this preprint. Click to download. 
- SupplFigure1.png

- SupplFigure2.png

- SupplFigure3.png

- SupplFigure4a.png

- SupplFigure4b.png

- SupplFigure4c.png

- SupplFigure5a.png

- SupplFigure5b.png

- SupplFigure5c.png

- SupplFigure5d.png

- SupplementaryTable1.docx

- SupplementaryTable2.docx

- SupplementaryTable3.docx

- SupplementaryTable4.docx

- SupplementaryTable5.docx

- SupplementaryTable6.docx

- SupplementaryTable7.docx 